\title{
Large-scale distribution of three deep-water squaloid sharks: Integrating data on sex, maturity and environment
}

Teresa Moura $^{\mathrm{a}, *}$, Emma Jones ${ }^{\mathrm{b}}$, Maurice W. Clarke ${ }^{\mathrm{c}}$, Charles F. Cotton ${ }^{\mathrm{d}}$, Paul Crozier ${ }^{\mathrm{e}}$, Ross K. Daley ${ }^{f}$, Guzman Diez ${ }^{g}$, Helen Dobby ${ }^{h}$, Jan E. Dyb ${ }^{i}$, Inge Fossen', Sarah B. Irvine ${ }^{\mathrm{j}}$, Klara Jakobsdottir ${ }^{\mathrm{k}}$, Luis J. López-Abellán', Pascal Lorance ${ }^{m}$, Pedro Pascual-Alayón', Ricardo B. Severino ${ }^{\text {, }}$, Ivone Figueiredo ${ }^{a}$

\footnotetext{
a Divisão de Modelação e Gestão de Recursos da Pesca, Instituto Português do Mar e da Atmosfera, Av. Brasília, 1449-006 Lisbon, Portugal

b National Institute of Water and Atmospheric Research, 41 Market Place, Auckland Central 1010, New Zealand

${ }^{c}$ Marine Institute, Rinville, Oranmore, Galway, Ireland

${ }^{d}$ Florida State University Coastal and Marine Lab, 3618 Coastal Hwy 98, St. Teresa, FL, USA

e World Wildlife Fund New Zealand, PO Box 6237, Marion Square, Wellington 6141, New Zealand

${ }^{f}$ CSIRO Wealth From Oceans Flagship, GPO Box 1538, Hobart 7001, TAS, Australia

${ }^{g}$ AZTI-Tecnalia, Marine Research Division, Txatxarramendi Ugartea z/g, 48395 Sukarrieta, Bizkaia, Spain

h Marine Scotland Science, Marine Laboratory, 375 Victoria Road, Aberdeen AB11 9DB, United Kingdom

'Møre Research, Section of Fisheries, PO Box 5075, Larsgård, N-6021 Ålesund, Norway

${ }^{j}$ Irvine Consulting, 617 Dorans Rd, Sandford 7020, TAS, Australia

${ }^{k}$ MRI, Marine Research Institute Iceland, Skúlagata 4, 121 Reykjavík, Iceland

I Centro Oceanográfico de Canarias, Instituto Español de Oceanografía, Vía Espaldón Dársena Pesquera Pcl. 8, 38180 Santa Cruz de Tenerife, Spain

m IFREMER, rue de L'lle d'Yeu, BP 21105, 44311 Nantes Cedex 3, France

${ }^{n}$ CIMAR Laboratório Associado/CIIMAR, Centro de Investigação Marinha e Ambiental, Universidade do Porto, Rua dos Bragas, 289, 4050-123 Porto, Portugal
}

*: Corresponding author : Teresa Moura, tel.: +351 213027131 ; email address : tmoura@ipma.pt

\begin{abstract}
:
Deep-water sharks exhibit species-specific reproductive strategies, which include segregation by sex, size and reproductive stage. However, due to the wide spatial distribution of most species, available information, usually collected at a regional scale, is usually not adequate to infer species reproductive spatial dynamics. This study draws together information on the distribution of reproductive stages of three species of squaliform sharks: Portuguese dogfish Centroscymnus coelolepis (Somniosidae), leafscale gulper shark Centrophorus squamosus (Centrophoridae) and birdbeak dogfish Deania calcea (Centrophoridae), gathering data from several geographical areas from the Atlantic, Indian and Pacific Oceans. For each species we analysed the sex ratio and the spatial patterns of reproductive stages within regions, considering the influence of geographical area, depth, season, temperature and
\end{abstract}


salinity. The combination of statistical methods used in this study successfully identified a number of life history patterns which reflect different use of habitats by sex and life cycle stage. Pregnant females of the three species are spatially segregated, inhabiting shallower and/or warmer waters. In the case of the leafscale gulper shark this segregation might be associated with large scale migrations. In contrast, in Portuguese dogfish all adult maturity stages occur in the same geographical area. Pregnant female birdbeak dogfish were rare in all samples. Larger immature specimens of all the three species distribute deeper than the remaining maturity stages in most of the regions analysed. Mature males of leafscale gulper shark and birdbeak dogfish were more broadly distributed than mature females, supporting the possibility of sex-biased dispersal. Neonates and small sized specimens were scarce in the Northeast Atlantic potentially explained by their concentration in nurseries, and/or by gear selectivity. Management measures will benefit from considering the geographic scale of demographic variation between species. However, standardized collaborative approaches will be needed for comprehensive assessment.

Keywords: Commercial fishery data ; Deep-sea ; Life stage ; Population structure ; Survey data 


\section{1. Introduction}

There is worldwide concern for the conservation of deep-water sharks due to low

4 biological productivity and population declines (Kyne and Simpfendorfer, 2010). Life history

5 characteristics typically include a slow growth rate, late age-at-maturity and low fecundity,

6 indicating long generation times (Garcia et al., 2008; Graham and Daley, 2011). Consequently,

7 populations that have declined will require decades or even centuries to recover (Pratt and

8 Casey, 1990; Simpfendorfer and Kyne, 2009).

Effective management of these species requires precautionary approaches founded on

10 an understanding of species-specific life histories (Simpfendorfer and Kyne, 2009). Life-history

11 traits are quite diverse among deep-water sharks, but some strategies, including segregation

12 patterns, are similar to other elasmobranch species (Wearmouth and Sims, 2008). Although

13 less studied than shallow-water species, segregation within a population by sex, size and/or

14 reproductive stage has been reported for a number of deep-water shark species (Muñoz-

15 Chapuli, 1984; Yano and Tanaka, 1988; Wetherbee, 1996; Girard and Du Buit, 1999; Clarke et

16 al., 2001; Jakobsdóttir, 2001; McLaughlin and Morrissey, 2005). Segregation may be

17 advantageous in a population to maximize reproductive success, minimize predation risk or

18 potential aggressive interactions, and for size or sex-specific foraging requirements (Sims,

19 2005; Wearmouth and Sims, 2008). Segregation can occur at different scales, and is often

20 linked to particular environmental or ecological features. The set of factors potentially

21 influencing segregation may be complex. Therefore, demographic data from the full range of a

22 population is fundamental to assessing status and particularly for predicting responses to

23 exploitation.

$24 \quad$ Attempts to develop adequate quantitative stock assessments for deep-sea sharks

25 have fallen short of expectations due to inadequate data, particularly in the Atlantic and

26 Southwestern Pacific. Information available on deep-water sharks is derived either from 
1 sampling of commercial catches or from scientific surveys. Fishery data are often restricted to

2 those deep-sea sharks that are of greatest commercial importance, and have been limited

3 historically by a lack of taxonomic and geographic precision. In contrast, fishery-independent

4 surveys are often temporally irregular, and none have had sufficient geographic coverage to

5 ensure that all demographic components of the populations are sampled. These deficiencies

6 are exacerbated by the global distribution of some species that include waters under many

7 jurisdictions, and also by their specific reproductive strategies where mating and pupping

8 might be decoupled in space and time, due to sperm storage (Moura et al., 2011a). Major

9 scientific investment is required to gain a full understanding of the spatial and temporal

10 population dynamics of deep-water sharks, and enable estimates of sustainable exploitation

11 levels to be derived.

12 The Portuguese dogfish (Centroscymnus coelolepis, Somniosidae), the leaf scale gulper

13 shark (Centrophorus squamosus, Centrophoridae) and the birdbeak dogfish (Deania calcea,

14 Centrophoridae) are viviparous sharks widely distributed on the mid-continental slope at

15 depths of 800-1600 $\mathrm{m}$ in the Atlantic, Indian and Pacific Oceans (Compagno et al., 2005).

16 These species reach $120-160 \mathrm{~cm}$ total length and are frequently caught by deepwater trawl

17 and bottom longline fleets (Stevens, 2003; Stevens and Correia, 2003; White, 2003). In the EU

18 waters, a zero total allowable catch (TAC) was adopted in 2010 for a variety of deep-water

19 sharks, including these species (Council Regulation (EU) No 1359/2008). In Australia, in

20 addition to a TAC regime, there are spatial/depth closures over some areas with important

21 historical catches (Woodhams et al., 2012). In the northwest Atlantic Ocean, southwest Indian

22 Ocean and in New Zealand, there are currently no management regulations for these species.

23 This study draws together regional knowledge of size distribution and reproductive

24 stages of three species of squaliform sharks. For each species, we analysed and compared the

25 spatial patterns within and among different regions of the Atlantic, Indian and Pacific Oceans,

26 using commercial and survey data. Spatial variation of the defined maturity groups was studied 
1 considering the influence of depth, temperature, salinity, area and season. The key findings are

2 presented in the context of regional management arrangements required to ensure

3 sustainability of populations.

4

\section{2. Material and methods}

6

7 2.1. Data sources

Biological data were collected onboard commercial trawl and longline fishing vessels,

10 and during research surveys conducted in six different ocean regions: northeastern (NE)

11 Atlantic Ocean (including the mid-Atlantic ridge), centre-eastern (CE) Atlantic Ocean,

12 southeastern (SE) Atlantic Ocean, northwestern (NW) Atlantic Ocean, southwestern (SW)

13 Indian Ocean and southwestern (SW) Pacific Ocean (Fig. 1; Table A1). All specimens were

14 caught within the bathymetric range of $200-3200 \mathrm{~m}$.

\subsection{Data collation and standardization}

The spatial and temporal resolution of the data varied among geographic areas due to

19 the logistical constraints associated with the different sampling methods (e.g. depth, gear,

20 duration, year, season). In order to allow the comparison of datasets from different sampling

21 years the distribution patterns of each species in each geographical area and region were

22 assumed to be temporally consistent.

A number of data standardization steps were applied to produce a single database. As

24 much of the data had been collected opportunistically, the geographic precision of the capture

25 locations varied among sources. Therefore, the first key step was to standardize locations by ocean 'region'. Data from NE Atlantic, SW Indian and SW Pacific regions were further classified 
1 by 'geographic area'. The second step was to ensure that the biological attributes recorded

2 were consistent among regions. Biological data provided for each specimen included the

3 species total length (TL), sex and maturity stage. Maturity stage data were standardized by

4 classifying each individual according to a maturity stage group. These groups are based on

5 Stehmann (2002) modified after by Figueiredo et al. (2008) and Irvine et al. (2012) (equivalent

6 stages indicated in parentheses). For males, two groups were considered: immature (immature

7 and maturing) and mature (mature and active). For females four groups were considered:

8 immature (immature and maturing), mature (mature - non-pregnant, pre-ovulatory), pregnant

9 (developing, differentiating and expecting) and post-natal (post-natal). Where regenerating

10 females (maturing, not for the first time) had been observed, they were combined with post-

11 natal stages. In the dataset from the SW Indian Ocean the information was not sufficient to

12 discriminate between post-natal and mature females.

13 Published studies show that neonates of these three species are scarce or entirely

14 absent from the NE Atlantic. This study examined a size-based subset of the data for immature

15 specimens for the same pattern. The term "juvenile" was used for small immature individuals

16 between length-at-birth and a pre-determined upper limit. These sizes were based on

17 published values from the NE Atlantic (Girard and Du Buit, 1999; Clarke et al., 2002; Figueiredo

18 et al., 2008) and were assumed to be applicable to other regions. Size-at-birth was taken as 25-

$1931 \mathrm{~cm}$ for the Portuguese dogfish (Moura et al., 2011b), 38-44 cm for the leafscale gulper shark

20 (Bañon et al., 2006; Figueiredo et al., 2008) and 28-33 cm for the birdbeak dogfish (Irvine et al.,

21 2012). The upper limit sizes applied were $<60 \mathrm{~cm}$ for the Portuguese dogfish and leafscale

22 gulper shark and $<55 \mathrm{~cm}$ for the birdbeak dogfish. Hereafter term "immature" will refer only to

23 the fraction of immature stage specimens above the upper size limit for juveniles. Juvenile and

24 immature specimens were only combined when estimating the proportion of maturity stages

25 by geographical area. 
2 assessing geographic distribution.

3

$4 \quad$ 2.3. Statistical analysis

5

All data analyses were conducted in the R software environment (R Core Team, 2012).

7 For each species-region combination, the relationship of maturity to depth was evaluated with

8 boxplots constructed using the package Lattice (Sarkar, 2008).

The influence of gear type (trawl or longline) on length and maturity stage was also

10 evaluated for the NE Atlantic region, where different types of gears were used for the

11 collection of the specimens.

13 2.3.1. Sex ratio

14 The influence of depth on sex ratio was examined for each species-area combination

15 by calculating the median and interquartile ranges of the proportion of females by depth strata

$16(100 \mathrm{~m})$. This analysis was restricted to geographical areas with 25 or more hauls of $>1$

17 individual. The depth intervals varied between species: $800-1700 \mathrm{~m}$ for the Portuguese dogfish, 500 -1700 $m$ for the leafscale gulper shark and 500-1400 m deep for the birdbeak dogfish. These intervals include the depths where each species were sampled more frequently.

\subsubsection{Mapping and occurrence of maturity stages}

For males and females, the proportion of individuals at each maturity stage was

23 described and plotted for each geographical area and region where sufficient data were

24 available (only datasets with maturity information for a total of 30 or more individuals were

25 considered). 
2 maturity stage was mapped using ArcGIS v.9.0. The analysis was restricted to observations

3 with precise geographic location. These data were overlaid on mapped coastline and

4 bathymetry data extracted from the General Bathymetric Chart of the Oceans (GEBCO) (IOC,

$5 \mathrm{IHO}$ and BODC, 2003).

6

\section{$7 \quad$ 2.3.3. Environmental variables and maturity} Temperature and salinity values were estimated for each haul, based on geographical

9 position and depth, using the World Ocean Atlas 2009 database from U.S. National

10 Oceanographic Data Center (Antonov et al., 2010; Locarnini et al., 2010) and the 3D estimation

11 method implemented in Ocean Data View Software (Schlitzer, 2011). 3D point estimation is a

12 fast weighted averaging procedure and combines the environmental information with user

13 specified longitude, latitude and depth, assuming specific averaging length scales (Schlitzer,

14 2011). Scales were considered as $2.5 \%$ of the axis ranges for longitude and latitude and $100 \mathrm{~m}$

15 for depth. Yearly environmental values were used in calculations because a preview of the

16 monthly data found only minor variation. Further, the monthly environmental data did not

17 cover the full depth range of the catch data. Constrained correspondence analysis (CCA) was used to explore how the maturity

19 stages of each species were influenced as a biological response to four environmental variables: temperature, salinity, depth and season. This analysis used the Vegan package for $R$

21 software (Oksanen, 2011). This method combines a multivariate ordination presence/absence

22 of maturity stage with a constrained regression maximizing the correlation between the

23 maturity stages ordination axes and the selected environmental variables. It was assumed that

24 the ecological range of each maturity stage analysed has been sampled and further assumed

25 that each maturity stage presents a unimodal response to each independent variable (ter

26 Braak, 1986; Borcard et al., 2011). It is pertinent to note that whilst the inertia (percentage of 
1 variation explained) is typically low $(<10 \%)$ when CCA is applied to binary variables, the results

2 can still be ecologically meaningful (ter Braak and Verdonschot, 1995; Oksanen, 2011). Two

3 matrices were constructed for this analysis: one corresponding to the occurrence of maturity

4 stages (presence/absence, dependent variable), and the other corresponding to the

5 environmental variables mentioned above (independent variables). CCA were fitted

6 conditioned to the geographical area, i.e. area was partially out from the analysis before

7 constraints, and only to regions with representative data ( $>100$ georeferenced hauls with

8 maturity information). The final selection of independent variables for inclusion in the CCA

9 model followed a stepwise process, based on the Aikaike information criterion (AIC). The

10 variance inflation factor (VIF) was used to avoid multicollinearity, i.e. inclusion of

11 environmental variables strongly correlated with each other (ter Braak, 1986; Oksanen, 2011).

12 VIFs $>10$ should be examined and avoided (Borcard et al., 2011). In cases where VIF $>10$, all the

13 possible combination of variables were considered in the CCAs. Variable selection considered

14 the Spearman correlation coefficient estimated between variables and the most rational

15 results for VIF, AIC and proportion of inertia explained. Results of the analysis were plotted and

16 scaled to maturity stages. Monte Carlo permutation tests were used to assess the significance

17 of the terms and axis of the model. In both cases a significance level of $5 \%$ was adopted.

18 The function "ordisurf", from the vegan R package was used for weighted fitting and

19 plotting of a smooth surface of the selected variables. This function fits the environmental

20 surface using thin plate splines in a generalized additive model (GAM), and then uses the

21 results to predict and plot the surface on an ordination diagram (Oksanen et al., 2012). This

22 analysis allows curvilinear relationships, and tests the linearity hypothesis of the biplot method

23 (Oksanen, 2011). It is important to note that this method enables the evaluation of trends for

24 each variable independently and is based on the proportion of variance explained by the

25 variables included in the model. 


\section{3. Results}

2

3.1. Portuguese dogfish

4

\subsubsection{Sampling details}

Portuguese dogfish data were obtained for all six regions and represented eighteen geographical areas. A total of 9388 specimens were recorded, of which up to 5940 individuals were selected for more detailed analysis, based on precision of recorded location and maturity

9 information. This number excluded individuals from SW Pacific, without geo-referenced data,

10 which were used solely to determine the proportion of individuals by maturity stage. Depth

11 and TL ranges by sex and maturity stage are reported in Figure 2 and Table A2. Maximum

12 length was sexually dimorphic in most regions and geographic areas, with females attaining

13 larger sizes than males. Exceptions were the SW Indian regions, New Zealand (SW Pacific) and

14 Tasmania (SW Pacific).

\subsubsection{Sex ratio}

Females outnumbered males in the NE Atlantic (with exception of the Bay of Biscay), in the CE Atlantic and in the SE Atlantic, whereas the opposite was observed for the SW Indian and SW Pacific Oceans (Table 1). Sex ratios varied within and between depth strata for all

20 geographical areas analysed (Fig. A1). In Scotland, Mauritania and Namibia the proportion of 21 females increased with depth.

\subsubsection{Mapping and occurrence of maturity stages}

Population structure varied between regions and geographical areas. In the NE Atlantic and in the SW Pacific (Australia) all maturity stages were sampled (Table 1, Fig. 3), with length ranges being similar among fishing gears in the first region (Fig. A2). For females, the 
1 proportions by different maturity stages were similar in some NE Atlantic geographical areas

2 (excluding Rockall and Hatton Banks, North Azores and Canarias) and in Tasmania. In these

3 areas, mature females accounted for around $17-25 \%$ of the samples, with pregnant females

4 making up 8-17\%. In contrast, the proportion of mature and immature males varied widely

5 within the NE Atlantic and SW Pacific regions. The pattern was different for other regions. In

6 the CE and SE Atlantic regions, mature, pregnant and post-natal females and mature males

7 were absent or seldom observed. In the NW Atlantic region, juveniles prevailed in the samples

8 and only one mature female was recorded. Some areas in the SW Indian region provided

9 contrast: off the Mozambique plateau, immature and mature females were most common,

10 with some pregnant females also recorded; off the Madagascar plateau, mature males were

11 more common and pregnant females made up nearly $30 \%$ of the female sample.

12 The number of juveniles caught varied among regions: zero or low numbers were

13 recorded in the NE Atlantic $(n=7)$, SW Indian $(n=0)$ and SW Pacific, Australia $(n=8)$, whilst much

14 higher numbers were reported for the NW Atlantic $(n=53)$, CE Atlantic $(n=796)$, with the

15 highest numbers recorded in the SE Atlantic $(n=695)$. Some of these were potentially

16 neonates since their sizes were close to the estimated length-at-birth. Most of the juvenile

17 specimens were caught by trawlers, with the exceptions being one individual caught by

18 longline in the NE Atlantic and a small portion of the NW Atlantic sample that was caught with 19 traps.

\subsubsection{Environmental variables and maturity}

For the NE Atlantic data (excluding juveniles, that were recorded in low number),

23 depth was the only factor selected in the CCA model. This model explained $10 \%$ of the total

24 inertia $\left(p_{\text {canonical relationship }}=0.005 ; p_{\text {axis }}=0.002\right)$. Depth was negatively correlated with axis 1 . The

25 ordination and surface model of the environmental variable selected showed that pregnant 
1 females had the shallowest distribution, mature males were deeper and all other stages

2 deeper still, and at closely located sites (deviance explained $=58 \%$ ) (Fig. 4).

All the other datasets were inadequate to run the CCA, either due to the low

4 representation of maturity groups (CE Atlantic and SE Atlantic datasets were composed mainly

5 of juveniles and immature specimens) or to insufficient data (as the case of NW Atlantic and

6 SW Indian Ocean). In the CE Atlantic, $68 \%$ of the juveniles caught occurred between 1300 and

$71500 \mathrm{~m}$ deep. Juveniles and immature specimens were caught in the same hauls, although

8 each haul was typically dominated by one group or the other. Those hauls clearly dominated

9 by juveniles were mostly located at centre-south slope of Mauritania. In the NW Atlantic,

10 juveniles were recorded from 670 to $2624 \mathrm{~m}$ but $88 \%$ of these catches were shallower than

$111000 \mathrm{~m}$. In the SW Indian Ocean, maturity stages were not correlated with depth.

13 3.2. Leafscale gulper shark

\subsubsection{Sampling details}

Data for the leafscale gulper shark were obtained for all regions of the Eastern Atlantic

17 and for the SW Pacific. A total of 5480 specimens were sampled, with up to 3483 meeting the criteria for inclusion in the statistical analyses. Depths and TL ranges by sex and maturity stage are reported on Figure 2 and Table A3. Females attained larger sizes than males for most geographical areas.

\subsubsection{Sex ratio}

In the NE Atlantic, sex ratios varied between areas. Males predominated over females

24 on the Rockall and Hatton Banks, off Ireland, Portugal, on the Mid Atlantic Ridge (Northern

25 Azores) and in Madeira (Table 2). Females were more frequently caught in the remaining

26 areas. In the northern areas of the NE Atlantic (Scotland and Ireland) the proportion of females 
1 increased with increasing depth although there was also high variability within each depth

2 strata (Fig. A3). In the CE Atlantic, males and females were caught in equal numbers, but

3 samples sizes were too low for more detailed analysis. In the SW Pacific (New Zealand),

4 females were significantly more abundant than males in the two geographical areas and sex

5 ratios were not influenced by depth.

6

$7 \quad$ 3.2.3. Mapping and occurrence of maturity stages

The proportions of maturity stages varied considerably among regions and

9 geographical areas (Table 2, Fig. 5). In the NE Atlantic, all the maturity stages were caught and

10 size ranges did not differ among fishing gears (Fig. A4). In this region, apart from Iceland,

11 mature males were more common than immature males, and were broadly distributed along

12 the continental slopes. In contrast, mature females were far less common, with immature

13 specimens dominating the catch, except around Iceland and further south around Madeira and

14 Canarias. Pregnant females were only recorded in three regions: off Iceland ( $n=5$ out of 36

15 females sampled), Portugal ( $n=3$ out of 122 females sampled) and from the Madeira

16 Archipelago ( $n=30$ out of 60 females sampled). Post-natal females were recorded from most

17 of the geographical areas except the Canarias and Madeira Archipelagoes and the mid-Atlantic

18 ridge north to the Azores. Despite the large sample sizes in many areas, only 3 juveniles were

19 caught from SW of the Portuguese mainland. These specimens, as well as all the other juvenile

20 specimens recorded from other regions, were caught using trawl nets. In the CE Atlantic,

21 immature specimens dominated the sample. Mature males were recorded all along the

22 surveyed slope. No mature females were caught in this area. The few records of this species in

23 the SE Atlantic included immature (including juveniles) and mature specimens from both

24 sexes. Around New Zealand in the SW Pacific region, immature individuals were dominant for

25 both males and females. Pregnant and post-natal females were rare ( $n=12$ and 4 out of 508 
1 females sampled, respectively). Juveniles occurred mainly on the northern slopes of the

2 Chatham Rise and also to the southwest of the South Island of New Zealand (Puysegur Bank).

3

4

5

6

7

8

9

10

\subsubsection{Environmental variables and maturity}

In the NE Atlantic, juveniles were excluded from the CCAs due to small sample sizes. In this region, depth and temperature were the environmental factors selected in the CCA model, explaining $16 \%$ of the total inertia $\left(p_{\text {canonical relationship depth }}=0.005 ; p_{\text {canonical relationship temperature }}=0.005\right.$; $p_{\text {axis1 }}=0.002 ; p_{\text {axis2 }}=0.002$ ). These two environmental variables were highly correlated with axis 1 , with depth being positively related and temperature being negatively related with this axis. Axis 2 was also negatively correlated with temperature. The surface model of the selected environmental variables indicated that the distribution of males was not related to depth or temperature, but post-natal and mature females tended to occur in relatively shallower sites (deviance explained $=76 \%$ and $53 \%$ for depth and temperature, respectively) (Fig. 6a and b). Pregnant females were distributed preferentially at warmer stations compared to the remaining maturity stages, particularly immature females, which were usually found at greater depths and lower temperatures.

In the SW Pacific data (excluding pregnant and post-natal females due to their low numbers in the samples), the best CCA model included only depth and salinity (6\% of the total inertia explained; $p_{\text {canonical relationship depth }}=0.002 ; p_{\text {canonical relationship salinity }}=0.075 ; p_{\text {axis } 1}=0.002 ; p_{\text {axis } 2}=$ 0.950). Depth was positively correlated with axis 1 and salinity was positively correlated to axis 2 , the latter explaining a small fraction of variation. The ordination and the surface models of the selected environmental variables showed that immature males, females and juveniles all co-occurred at relatively deeper and less saline waters (deviance explained $=96.5 \%$ and $100 \%$ for depth and salinity, respectively) (Fig. $6 \mathrm{c}$ and d). Mature males were associated with shallower, more saline waters. Nine of the twelve females were found in waters shallower than $900 \mathrm{~m}$. The two post-natal females sampled in the South Island were collected from 
1 depths shallower than $650 \mathrm{~m}$, whereas those sampled in the Chatham Rise and North Island

2 were both collected in the $900 \mathrm{~m}$ stratum. Sample sizes from the CE Atlantic and SE Atlantic were insufficient for CCA ( $n=26$ and

413 hauls, respectively), but differences in maturity stages occurrence were also found to be

5 related with depth. In the CE Atlantic, $75 \%$ of the juveniles occurred $<900 \mathrm{~m}$ deep, at similar

6 depths to mature males, whereas immature specimens were found relatively deeper. In the SE

7 Atlantic, juveniles $(n=4)$ were caught between 550 and $800 m$ deep, shallower than all other

8 maturity stages.

9

10 3.3. Birdbeak dogfish

$12 \quad$ 3.3.1. Sampling details

13 Data were obtained from the Atlantic and the SW Pacific. A total of 14468 specimens

14 was collected, of which 12189 met the criteria for inclusion in the statistical analysis. Depth

15 and TL ranges by sex are reported in Figure 2 and Table A4. In all the areas sampled, females

16 attained larger sizes than males.

3.3.2. Sex ratio

Sex ratios varied between regions. For the NE Atlantic region, males predominated

20 over females at most sampling locations, except in the Bay of Biscay, Portugal and Canarias

21 Archipelago (Table 3). In this region sex ratios were variable among depth strata, but with no

22 discernable trend (Fig. A5). In the CE Atlantic, females predominated over males but in the SE

23 Atlantic the contrary was observed. In these two regions the proportion of females decreased

24 with depth. In the SW Pacific region (New Zealand), the numbers of males and females were

25 similar off the South Island but on the Chatham Rise and around the North Island, females 
1 were more common than males. In this area, the proportion of females seemed to decrease

2 with depth, despite the high variability observed (wide interquartile ranges).

3

$4 \quad$ 3.3.3. Mapping and occurrence of maturity stages

5

6

7

8

9

10

11

12

13

14

15

The proportion of maturity stages observed varied considerably among geographical areas and regions (Table 3, Fig. 7). In the NE Atlantic, specimens of all maturity stages were caught and size ranges were similar among fishing gears (Fig. A6). In this region, mature males were widely distributed, but their proportion was variable among geographical areas.

Immature females outnumbered mature females in almost all regions, except the Canarias Archipelago. The number of pregnant females was low or totally absent in most geographical areas. Post-natal females were mainly recorded in northern areas, often spatially separated from other stages. In this region, juveniles were caught both with trawls and longlines, and were recorded on Hatton Bank $(n=10)$, off Ireland $(n=2)$ and on the SW Portugal mainland $(n=$ 5), but representing less than $1 \%$ of the total sample from these areas. In contrast, the central and southern areas of the eastern Atlantic, off the coasts of Mauritania (CE Atlantic) and Namibia (SE Atlantic), much higher numbers of juveniles were caught, representing 38 - $41 \%$ of the samples (all caught with trawl nets). In the CE Atlantic, immature females and males (including juveniles) made up over $90 \%$ of the specimens caught. Further south, in the SE Atlantic region, immature specimens also accounted for a large percentage of the catches ( $50 \%)$. Here, pregnant and post-natal females were entirely absent. In the SW Pacific around New Zealand, mature males made up nearly $90 \%$ of males caught from the Campbell Plateau, and $63 \%$ further north on the Chatham Rise and off the North Island., immature females (including juveniles) were more common, making up over $78 \%$ of females examined. Pregnant and post-natal females were common around North Island but were absent from the Campbell Plateau. Juveniles were caught by trawl nets in both areas for which data were available, and 
1 were far more common on the Chatham Rise and North Island shelf ( $23 \%$ of specimens caught)

2 than around the Campbell Plateau further south (2.8\%).

3

\section{$4 \quad$ 3.3.4. Environmental variables and maturity}

In the NE Atlantic, depth was the leading environmental factor selected by the CCA

6 model, explaining $12 \%$ of the total inertia ( $p_{\text {canonical relationship depth }}=0.005 ; p_{\text {axis } 1}=0.002$ ). Juveniles

7 were excluded from this analysis due to low numbers. Depth was positively correlated with

8 axis 1 . The ordination of the maturity stages and the overlaid surface model for depth showed

9 that mature males and both immature males and females tended to occur at greater depths,

10 while pregnant, post-natal and mature females were associated with relatively shallower

11 depths (deviance explained=80\%) (Fig. 8a).

12 In the SW Pacific New Zealand data, the CCA adjustment showed multicollinearity for

13 temperature, depth and season. As a result the selected model just included salinity and

14 temperature ( $10 \%$ of the total inertia explained; $p_{\text {canonical relationship temperature }}=0.005 ; p_{\text {canonical }}$

15 relationship salinity $=0.005 ; p_{\text {axis } 1}=0.002 ; p_{\text {axis2 }}=0.002$ ). Temperature was highly negatively correlated

16 with axis 1 whereas salinity was primarily correlated (negatively) with axis 2 . The ordination of

17 the maturity stages overlaid on the surface models of each selected variable showed that post-

18 natal and pregnant females occurred in warmer and higher salinity waters (deviance

19 explained $=99.5 \%$ and $96.1 \%$ for temperature and salinity, respectively) (Fig. 8b,c). Mature

20 males were associated with deeper sites and juveniles with intermediate temperatures and

21 salinity values.

22 The CE Atlantic and SE Atlantic datasets were not adequate for CCA because they were

23 dominated by immature specimens. In the CE Atlantic $92 \%$ of the juveniles occurred shallower

24 than $1000 \mathrm{~m}$. Juveniles and immature specimens co-occurred in the same hauls but each

25 instance either juveniles or immature specimens clearly dominated. 


\section{4. Discussion}

Progress in understanding the population structure of the Portuguese dogfish,

3 leafscale gulper shark and birdbeak dogfish has been impaired by the difficulty of compiling

4 and comparing data from the many different geographical areas and jurisdictional waters

5 where these species occur. This study combined available biological information from research

6 surveys and sampling of commercial catch to understand the population dynamics of these

7 species within each region. However, the likely effects of different fishing gears limited some

8 analyses among areas and within regions to qualitative or semi-quantitative descriptions.

9 Previously published finer-scale spatial resolution analysis identified that size frequencies and

10 selectivity ogives for Portuguese dogfish and birdbeak dogfish off Ireland differed between

11 trawls and longlines (Clarke et al., 2005). In this study, trawls and longlines adequately

12 sampled all maturity stages and sizes, except for juveniles, which were primarily caught with

13 trawls. It was hoped that the use of presence/absence of maturity stages in each haul

14 minimized this gear effect.

4.1. Species distribution

The combined data for the Portuguese dogfish, leafscale gulper shark and birdbeak

19 dogfish indicate that all three species are widely distributed at a global scale. Regional

20 differences in bathymetric distributions were observed; the leafscale gulper shark specimens

21 were mainly caught between 600 and $1500 \mathrm{~m}$ in the NE Atlantic, with occasional records in

22 down to $3300 \mathrm{~m}$. The depth range from the New Zealand region (SW Pacific) extended into

23 shallower water ( $361 \mathrm{~m}$ ) to at least $1250 \mathrm{~m}$ (with $1300 \mathrm{~m}$ the maximum depth sampled in this

24 region). Its average range clearly overlaps that of the birdbeak dogfish, but is shallower than that of the Portuguese dogfish, which was regularly sampled as deep as $2000 \mathrm{~m}$, with 
1 occasional records down to $2800 \mathrm{~m}$. Spatial distribution patterns also differed among species,

2 as discussed below.

3

4 4.2. Sex ratio and population segregation

5

Variations in sex ratio must be considered when assessing species population

7 dynamics, particularly in those areas where fishing pressure is high. In all three species, sex

8 ratio varied with, geographical area and is likely to vary with depth. This variability might be

9 associated with sex or maturity stage segregation and requires a more detailed data.

10 The three species share some similarity in patterns of distribution by sex and maturity

11 stage. For example, pregnant females tended to be spatially segregated from the rest of the

12 population, as well as mature and post-natal females of leafscale gulper shark and birdbeak

13 dogfish. The distribution of the different reproductive stages has often been related to depth

14 (e.g. Yano and Tanaka, 1988; Girard and Du Buit, 1999; Clarke et al., 2002), and depth was

15 shown to be an important factor in the distribution of all three species in this analysis.

16 Temperature and salinity were also important. Results suggest that habitat requirements

17 change through the different life phases of these sharks. Season was not found to significantly

18 affect the occurrence of maturity stages, which likely reflects the longer-than-annual

19 reproductive cycle known to occur in squaliform sharks (Kyne and Simpfendorfer, 2010).

20 Despite relatively extensive sampling of research and commercial catches in the NE

21 Atlantic, neonates and small immature specimens (juveniles) were scarce for all three species,

22 as previously reported in a number of individual studies (Girard and Du Buit, 1999; Clarke et

23 al., 2002; Bañon et al., 2006; Figueiredo et al., 2008; Severino et al., 2009). In contrast, high

24 numbers of juveniles were caught in other areas such as CE Atlantic, SE Atlantic, and SW

25 Pacific. The data collected in these regions are not adequate to confidently infer the habitat

26 preferences of neonates and smaller immature specimens in the NE Atlantic. However, the 
1 absence of these small fish in the NE Atlantic may be a consequence of their concentration in

2 nurseries outside the sampling areas, movement to/ occurrence in pelagic (Compagno et al.,

3 1991) or deeper waters (Jakobsdóttir, 2001; Bañon et al., 2006) and/or by gear selectivity

4 (Irvine et al., 2012).

5 The concentration of juvenile sharks in nurseries, defined by Heupel et al. (2007) as aggregations in spatially separated locations repeatedly used across years, is a relatively common phenomenon in elasmobranchs. Such areas are suggested to provide suitable habitats for somatic growth due to high prey abundance and low mortality rates, although this assumption might not always hold true (Heupel et al., 2007). In Japan, juveniles of the closely related Owston's dogfish (Centroscymnus owstonii, Somniosidae) were found outside Suruga

11 Bay, in around 300-800 $\mathrm{m}$ water depth, shallower than the adult population (Yano and Tanaka

12 1988). Spiny dogfish (Squalus acanthias, Squalidae) neonates, poorly documented off the US

13 east coast, were recently found in a particular area, in shallower and colder waters than the

14 adults, and also associated with a different type of substrate (Sulikowski et al., 2013). The existence of nursery areas seems a plausible explanation for the high numbers of neonates and smaller immature fish observed in particular locations comparative to other areas of the overall distribution range for the species in this study. Another possible explanation for these early life stages being poorly documented in the NE Atlantic region is gear selectivity. Trawl nets using comparatively smaller mesh codends were used in CE Atlantic, SE Atlantic, and SW Pacific, and could have resulted in a higher

21 retention of juveniles, as has been previously reported for the birdbeak dogfish in the SW

22 Pacific (Irvine et al., 2012). However, it is unlikely that differences in size composition could only be ascribed to gear selectivity since small-sized species, such as the lantern sharks

24 (Etmopterus spinax and Etmopterus pusillus, Etmopteridae; maximum $\mathrm{TL}=60 \mathrm{~cm}$ and $50 \mathrm{~cm}$, respectively, Compagno et al., 2005), are frequently caught by the longline fisheries (e.g.

26 Armstrong, 2010), and in research trawl surveys. It should be noted that data from the SW 
1 Pacific (New Zealand) for the leafscale gulper shark and for the birdbeak dogfish indicated that

2 juvenile specimens co-occurred with other maturity stages in some areas, e.g., the northern

3 slopes of the Chatham Rise and on Puysegur Bank south of New Zealand. In the CE Atlantic,

4 where a significant concentration of juveniles was also observed, an experimental longline

5 haul fished approximately $15 \mathrm{~m}$ off the sea floor and captured only large specimens which

6 were seldom recorded in the trawl samples (P. Pascual, personal communication). These

7 observations suggest that juveniles and adults of the three species might co-occur in the same

8 area or potential nurseries, but have different habitat and / or prey choices, with juveniles

9 being more benthic than adults. In fact, ontogenetic differences in the diet are usually

10 reported for elasmobranchs with modifications from a benthic to a pelagic feeding strategy in

11 some species (Farias et al., 2006; Hallett and Daley, 2011).

12 Given the results presented here, it is likely that a combination of factors could be

13 hampering the detection of juveniles in the NE Atlantic. Further investigations in the NE

14 Atlantic should include experiments to test habitat hypotheses, such as sampling greater

15 depths, "untrawlable" hard substrates and the use of vertical longlines to assess the relative

16 position of the different life stages in the water column.

The probability of occurrence of larger immature specimens (> 55 or $60 \mathrm{~cm}$ ) of all three species increased with depth (particularly for females), with the exception of the birdbeak dogfish in SW Pacific. In addition, immature specimens of both sexes of Portuguese dogfish and birdbeak dogfish may aggregate according to age or size, as suggested by the CCA models. Mature males of leafscale gulper shark and birdbeak dogfish were more broadly

22 distributed than mature females, supporting the possibility of sex-biased dispersal in these

23 species. A genetic population study has shown that male leafscale gulper sharks have higher

24 levels of male-mediated gene flow in comparison to females, which were found to have more

25 limited dispersal (Verissimo et al., 2012). Sex-biased dispersal has been documented for other

26 shark species (Pardini et al., 2001; Portnoy et al., 2010; Daly-Engel et al., 2012) and has been 
1 related to the reproductive philopatry of females that, in some elasmobranchs species, return

2 to specific areas to give birth (Hueter et al., 2005). The aggregation of pregnant females of all the three species preferentially occurred at

4 relatively warmer and/or shallower depths. These conditions are favorable to embryonic

5 development as physiological processes are accelerated (Economakis and Lobel, 1998;

6 Robbins, 2007). Another possible trigger for segregation might be related to specific nutritional

7 requirements of pregnant females that could necessitate their migration to particular grounds.

8 In the case of the birdbeak dogfish, matrotrophy appears to occur (Paiva et al., 2012), whilst

9 the Portuguese dogfish and leafscale gulper shark are assumed to be lecithotrophic (Moura et

10 al., 2011b; Figueiredo et al., 2008), although the existence of supplemental maternal

11 nourishment (e.g. histotrophy) has never been studied in the latter.

\section{4.3. Portuguese dogfish}

15 The Portuguese dogfish was the only species where mature and pregnant females were

16 regularly caught in multiple regions, with mature fish often comprising over $50 \%$ of all females

17 sampled (e.g. NE Atlantic and Australia, SW Pacific). The occurrence of all adult reproductive stages within the same geographical area and, in many cases in similar proportions, suggests that this species is able to complete its life cycle within these areas. However, this is not

20 incompatible with a widespread mixing across the continuous distribution of the species.

21 Indeed, an apparent lack of genetic structure was found for the NE and CE Atlantic, and a large

22 scale migration of the NE specimens to the CE Atlantic waters to give birth has been proposed

23 (Verissimo et al., 2011). However, the capture of even low numbers of small specimens, post-

24 natal and pregnant females with near-term embryos in a number of areas of the NE Atlantic

25 (Girard and du Buit, 1999; Clarke et al., 2001; Bañon et al., 2006; Figueiredo et al., 2008), 
1 suggests that the existence of undiscovered concentration areas of juveniles in the NE Atlantic

2 may also be hypothesized.

3 The only other published studies for this species outside the NE Atlantic are from

4 Suruga Bay (Japan), and are in agreement with those presented here: all maturity stages

5 except juveniles were commonly found, and sexual segregation was evident, with pregnant

6 and mature females commonly found shallower than the remaining specimens (Yano and

7 Tanaka, 1984; 1988).

8

9 4.4. Leafscale gulper shark

In most regions, immature females of leafscale gulper shark predominated over

12 mature females, and pregnant individuals were rare. The distribution pattern formerly

13 assumed for this species in the NE Atlantic is based on the proposed existence of a large scale

14 migration, where females would give birth off the Madeira Archipelago, from which there are

15 reports of pregnant females (Severino et al., 2009). In the combined dataset presented here,

16 pregnant females were also found off Iceland, indicating another potentially important

17 reproductive area in the northern part of the NE Atlantic. Occasional captures of pregnant

18 females off Portugal and off Galicia have also been reported (Bañon et al., 2006). The existence

19 of migratory patterns for this species is proposed for the SW Pacific too, where all the maturity

20 stages were present (although with pregnant females being rare), but were associated with

21 specific geographical areas at a certain time in their life cycle. Our data also suggest the

22 existence of at least two nursery grounds along western Africa, in Mauritania and Namibia, but

23 no genetic differentiation between Eastern Atlantic and South Africa has been detected yet

24 (Verissimo et al., 2012).

\subsection{Birdbeak dogfish}


All life stages of the birdbeak dogfish were recorded in most of the regions analysed,

3 although with some differences in the proportions of maturity stages (or lack of some) among

4 geographical areas. Based upon the minimal size overlap between specimens caught off

5 Ireland and those caught off Portugal, Clark et al. (2002) suggested that the birdbeak dogfish

6 undergoes a migration along continental slopes between Irish and Portuguese waters, similar

7 to that has been postulated for New Zealand populations, where extensive migrations

8 associated with reproduction are thought to occur (Clark and King, 1989). Our data support

9 breeding migrations. However, in the NE Atlantic, all maturity stages, including pregnant and

10 post-natal females, were present in almost all areas, and at least $50 \%$ of males were mature.

11 Juveniles were caught in small numbers on Hatton Bank and off the SW of Portugal, suggesting

12 the existence of more than one nursery area, likely at shallower depths. In the CE and SE

13 Atlantic, despite the dominance of immature specimens, mature fish were also relatively

14 common (more evident in the SE Atlantic), but pregnant and post-natal females were scarce or

15 lacking. In New Zealand waters, juvenile fish were abundant, particularly on the Chatham Rise

16 and off the eastern coast of the North Island, but the proportions of mature fish varied by

17 geographical area. Pregnant females were encountered in low numbers, and only on Chatham

18 Rise and around the North Island. The results suggest the existence of population partitioning

19 according to life stage, particularly for pregnant stages, despite their rarity. Similarly, the

20 occurrence of pregnant females was rare on the Australian continental slope (Irvine et al.,

21 2012). Here, juveniles $(30-60 \mathrm{~cm})$ were the major component of the catch in shallower depth

22 strata (700-900 m) reflecting possible regional differences compared to the New Zealand

23 population, where juveniles were found at intermediate depths, in relation to other maturity

24 stages. 
2 spatial and temporal distribution of the demographic components of their populations

3 (Wearmouth and Sims, 2008). This knowledge is required for the development of management

4 measures that ensure the stability of their demographic structure (Simpfendorfer and Heupel,

5 2004), especially in cases where exploitation impacts differ at regional scales. The

6 identification of the life stages most critical and vulnerable to exploitation is also essential, and

7 if adequate information is made available, it will be possible to establish specific regulations,

8 probably spatially/depth structured, to preserve those stages as well as their essential habitats

9 (Simpfendorfer and Heupel, 2004). The present study contributes to these management goals

10 by compiling many different data sources to make progress in elucidating the likely population

11 structure, habitats and migration patterns of deep-water sharks. The resulting hypotheses

12 need to be tested in future studies, particularly to elucidate migrations, and further investigate

13 spatial distribution and preferential habitats for these three species.

14 Despite some similarities in the distribution patterns of the three species studied,

15 there are differences in habitat usage by sex and by life history stage. Given their scarcity in

16 our data, it is likely that neonates and small immature sharks, and pregnant female leafscale

17 gulper shark and birdbeak dogfish (in some regions), are not directly impacted by current

18 fishing pressure. However, it is important to note that the protection of nursery areas alone

19 may not be sufficient to conserve a shark population (Kinney and Simpfendorfer, 2009). The

20 available data also suggests that these fisheries have impacted only portions of the whole

21 population and distribution area of these three species: the spatial extent of commercial

22 fishing is limited and is therefore unlikely to overlap with their full distribution.

This study was innovative in collating worldwide information for these wide-ranging

24 species. The continuation of such collaborative data pooling is essential to update life-history

25 data, spatial and temporal information. It is also necessary to implement standardized, long-

26 term and broader-scale monitoring programs that will enable the determination of the stock 
1 status (Ward-Paige et al., 2012). There is currently no standardized sampling at a global scale,

2 but coordinated efforts are required for adequate stock assessments as well as monitoring the

3 impacts of fishing on these species. Future studies should also focus on other ecological factors

4 influencing the demographic-specific distributions of each population, such as oceanographic

5 conditions, substrate characterization and prey interactions. Such factors are important for

6 understanding the response of populations to either anthropogenic-induced changes or

7 environmental variations.

8

\section{Acknowledgements}

11 The authors would like to thank Miguel Santos and Jim O. Roberts for their support with

12 mapping software and climatological grid data extraction, respectively. We also thank Andy

13 Williston and Jack Musick (NW Atlantic), Malcolm Clark (New Zealand), Deep-C project

14 (www.deep-c.org; Gulf of Mexico) and TUBAPROF (MARE 22-05-01-FEDER-00028; Portugal) for

15 their assistance in collating, interpreting data and/or providing data for this study. We are also

16 grateful to the two anonymous reviewers for their helpful comments. T. Moura and I.

17 Figueiredo were partially supported by PNAB (EU DCR) and CERTIFICA (PROMAR 31-03-01-FEP-

18 0032). The contribution of T. Moura, G. Diez, K. Jakobsdottir, P. Lorance and I. Figueiredo

19 received financial support from the and FP7-DEEPFISHMAN project (Management and

20 monitoring of deep-sea fisheries and stocks, Grant agreement no.: 227390). The contribution

21 of E. Jones was funded by an International Mobility Fund grant from the Royal Society of New

22 Zealand (contract no: ISATA10-29).

23

24 References 
1 Antonov, J.I., Seidov, D., Boyer, T.P., Locarnini, R.A., Mishonov, A.V., Garcia, H.E., Baranova, O.K., Zweng, M.M., Johnson, D.R., 2010. Volume 2: Salinity., in: Levitus, S. (Ed.), World Ocean Atlas 2009. NOAA Atlas NESDIS 69, U.S. Government Printing Office, Washington, D.C.

Armstrong, M., 2010. Joint data collection between the fishing sector and the scientific community in Western Waters. Final Report to the European Commission, DirectorateGeneral for the Fisheries and Maritime Affairs. Contract SI2.491885, Ref. FISH/2007/03 Lot 1.

Bañon, R., Piñeiro, C., Casas, M., 2006. Biological aspects of deep-water sharks Centroscymnus coelolepis and Centrophorus squamosus in Galician waters (north-western Spain). J. Mar. Biol. Ass. UK 86, 843-846.

Borcard, D., Gillet, F., Legendre, P., 2011. Numercal Ecology with R. Springer, New York, USA.

Clark, M.R., King, K.J., 1989. Deepwater fish resources off the North Island, New Zealand: results of a trawl survey, May 1985 to June 1986. New Zealand Fisheries Technical Report 11.

Clarke, M.W., Connolly, P.L., Bracken, J.J. , 2001. Aspects of reproduction of the deep-water sharks Centroscymnus coelolepis and Centrophorus squamosus from west of Ireland and Scotland. J. Mar. Biol. Ass. UK 81, 1019-1029.

Clarke, M.W., Connolly, P.L., Bracken, J.J., 2002. Catch, discarding, age estimation, growth and maturity of the squalid shark Deania calceus west and north of Ireland. Fish. Res. 56, 139153.

Clarke, M.W., Borges, L., Officer, R.A., 2005. Comparisons of Trawl and Longline Catches of Deepwater Elasmobranchs West and North of Ireland. J. Northw. Atl. Fish. Sci. 35, 429442. Collins Publishers, London. 
1 Compagno, L.J.V., Ebert, D.A., Cowley, P.D., 1991. Distribution of offshore demersal

2 cartilaginous fish (class Chondrichthyes) off the west coast of southern Africa, with notes

3 on their systematics. South African Journal of Marine Science 11, 43-139.

Daly-Engel, T.S., Seraphin, K.D., Holland, K.N., Coffey, J.P., Nance, H.A., Toonen, R.J., Bowen, B.W., 2012. Global phylogeography with mixed-marker analysis reveals male-mediated dispersal in the endangered scalloped hammerhead shark (Sphyrna lewini). PLoS ONE 7, e29986.

Economakis, A.E., Lobel, P.S., 1998. Aggregation behavior of the grey reef shark, Carcharhinus amblyrhynchos, at Johnston Atoll, Central Pacific Ocean. Environ. Biol. Fish. 51, 129-139.

Farias, I., Figueiredo, I., Moura, T., Gordo, L., Neves, A., Serra-Pereira, B., 2006. Diet comparison of four ray species (Raja clavata, Raja brachyura, Raja montagui and Leucoraja naevus) caught along the Portuguese continental shelf. Aquat. Living Resour. 19, 105-114.

Figueiredo, I., Moura, T., Neves, A., Gordo, L.S., 2008. Reproductive strategy of leafscale gulper shark, Centrophorus squamosus, and Portuguese Dogfish, Centroscymnus coelolepis, on the Portuguese continental slope. J. Fish. Biol. 73, 206-225.

Garcia, V.B., Lucifora, L.O., Myers, R.A., 2008. The importance of habitat and life history to extinction risk in sharks, skates, rays and chimaeras. P. Roy. Soc. B - Biol. Sci. 275, 83-89. Girard, M., Du Buit, M.H., 1999. Reproductive biology of two deep-water sharks from the British Isles, Centroscymnus coelolepis and Centrophorus squamosus (Chondrichthyes: Squalidae). J. Mar. Biol. Ass. UK 79, 923-931.

Graham, K.J., Daley, R.K., 2011. Distribution, reproduction and population structure of three gulper sharks (Centrophorus, Centrophoridae) in southeast Australian waters. Mar. Freshwater Res. 62, 583-595.

Hallett, C.S., Daley, R.K., 2011. Feeding ecology of the southern lanternshark (Etmopterus baxteri) and the brown lanternshark (E. unicolor) off southeastern Australia. ICES J. Mar. Sci. $68,157-165$. 
1 Heupel, M.R., Carlson, J.K., Simpfendorfer, C.A., 2007. Shark nursery areas: concepts,

2 definition, characterization and assumptions. Mar. Ecol. Prog. Ser. 337, 287-297.

3 Hueter, R.E., Heupel, M.R., Heist, E.J., Keeyney, D.B ., 2005. Evidence of philopatry in sharks

$4 \quad$ and implications for the management of shark fisheries. J. Northw. Atl. Fish. Sci. 35, 239-

5247.

6 IOC, IHO, BODC, 2003. Centenary Edition of the GEBCO Digital Atlas. Published on CD-ROM on behalf of the Intergovernmental Oceanographic Commission and the International Hydrographic Organization as part of the General Bathymetric Chart of the Oceans; British Oceanographic Data Centre, Liverpool.

Irvine, S.B., Daley, R.K., Graham, K.J., Stevens, J.D., 2012. Biological vulnerability of two commercial gulper sharks (Deania, Centrophoridae) from southeastern Australia. J. Fish. Biol. 80, 1181-1206.

Jakobsdóttir, K.B., 2001. Biological aspects of two deep-water squalid sharks: Centroscyllium fabricii (Reinhardt, 1825) and Etmopterus princeps (Collett, 1904) in Icelandic waters. J. Fish. Biol. 51, 247-265.

Kinney, M.J., Simpfendorfer, C.A., 2009. Reassessing the value of nursery areas to shark conservation and management. Conserv. Lett. 2, 53-60. J.A., Heithaus, M.R. (Eds.), Sharks and their relatives II - biodiversity, adaptive physiology, and conservation. CRC Press, Boca Raton, pp. 37-113. M.M., Johnson, D.R., 2010. Volume 1: Temperature, in: Levitus, S. (Ed.), World Ocean Atlas 2009. NOAA Atlas NESDIS 68, U.S. Government Printing Office, Washington, D.C. the Cayman Trench, Jamaica. J. Mar. Biol. Ass. UK 85, 1-8. 
1 Moura, T., Serra-Pereira, B., Gordo, L.S., Figueiredo, I., 2011a. Sperm storage in males and

2 females of the deepwater shark Portuguese dogfish with notes on oviducal gland

3 microscopic organization. J. Zool. 283, 210-219.

4 Moura, T., Nunes, C., Bandarra, N., Gordo, L.S., Figueiredo, I., 2011b. Embryonic development

5 and maternal-embryo relationships of the Portuguese dogfish Centroscymnus coelolepis.

$6 \quad$ Mar. Biol. 158, 401-412.

7 Muñoz-Chapuli, R., 1984. Éthologie de la reproduction chez quelques requins de l'Atlantique nord-est. Cybium 8, 1-14.

9 Oksanen, J., 2011. Multivariate Analysis of Ecological Communities in R: vegan tutorial. Available at http://cc.oulu.fi/ jarioksa/opetus/metodi/vegantutor.pdf (accessed 22 February 2013).

Oksanen, J., Blanchet, F.G., Kindt, R., Legendre, P., Minchin, P.R., O’Hara, R.B., Simpson, G.L., Solymos, P., Stevens, M.H.H., Wagner, H., 2012. Vegan: Community Ecology Package. R package version 2.0-4. http://CRAN.R-project.org/package=vegan (accessed 22 February 2013).

Paiva, R.B., Neves, A., Sequeira, V., Nunes, M.L., Gordo, L.S., Bandarra, N., 2012. Reproductive strategy of the female deep-water shark birdbeak dogfish, Deania calcea: lecithotrophy or matrotrophy? J. Mar. Biol. Ass. UK 92, 387-394.

Pardini, A.T., Jones, C.S., Noble, L.R., Kreiser, B., Malcolm, H., Bruce, B.D., Stevens, J.D., Cliff, G., Scholl, M.C., Francis, M.P., Duffy, C.A.J., Martin, A.P., 2001. Sex-biased dispersal of great white sharks. Nature 412, 139-140.

Portnoy, D.S., McDowell, J.M., Heist, E.J., Musick, J.A., Graves, J.E., 2010. World phylogeography and male-mediated gene flow in the sandbar shark, Carcharhinus plumbeus. Mol. Biol. 10, 1994-2010. fisheries, with a review of Holden's method of estimating growth parameters, in: Pratt Jr, 
H.L.S., Gruber, H., Taniuchi, T. (Eds.), Elasmobranchs as Living Resources: advances in the biology, ecology, systematics and the status of the fisheries. NOAA Technical Report NMFS 90, 97-109.

R Core Team, 2012. R: A language and environment for statistical computing. R Foundation for Statistical Computing, Vienna, Austria. ISBN 3-900051-07-0. http://www.R-project.org (accessed 22 February 2013).

Robbins, R.L., 2007. Environmental variables affecting the sexual segregation of great white sharks Carcharodon carcharias at the Neptune Islands South Australia. J. Fish. Biol. 70, 1350-1364.

Sarkar, D., 2008. Lattice: Multivariate Data Visualization with R. Springer, New York.

11 Schlitzer, R., 2011. Ocean Data View. http://odv.awi.de (accessed 22 February 2013).

12 Severino, R., Afonso-Dias, I., Delgado, J., Afonso-Dias, M., 2009. Aspects of the biology of the 13 leaf-scale gulper shark Centrophorus squamosus (Bonnaterre, 1788) off Madeira 14 archipelago. Arquipélago - Life Mar. Sci. 26, 57-61.

Simpfendorfer, C.A., Heupel, M.R., 2004. Assessing habitat use and movement, in: Carrier, J.C., Musick, J.A., Heithaus, M.R. (Eds.), Biology of Sharks and their Relatives. CRC Press, Boca Raton, pp. 553-572.

Simpfendorfer, C.A., Kyne, P.M., 2009. Limited potential to recover from overfishing raises concerns for deep-sea sharks, rays and chimaeras. Environ. Conserv. 36, 97-103.

Sims, D.W., 2005. Differences in habitat selection and reproductive strategies of male and female sharks, in: Ruckstuhl, K.E., Neuhaus, P. (Eds.), Sexual Segregation in Vertebrates: Ecology of the Two Sexes. Cambridge University Press, New York, pp. 127-147. cartilaginous fishes (Pisces, Chondrichthyes). Arch. Fish. Mar. Res. 50, 23- 48. 
1 Stevens, J., Correia, J.P.S., 2003. Centroscymnus coelolepis. In: IUCN 2011. IUCN Red List of Threatened Species. Version 2011.1. http://www.iucnredlist.org (accessed $29^{\text {th }}$ September 2011).

Sulikowski, J.A., Prohaska, B.K., Carlson, A.E., Cicia, A.M., Brown, C.T., Morgan, A.C., 2013. Observations of neonate spiny dogfish, Squalus acanthias, in Southern New England: A first account of a potential pupping ground in the Northwestern Atlantic. Fish. Res. 137, 59-62.

ter Braak, C.J.F., 1986. Canonical correspondence analysis: a new eigenvector method for multivariate direct gradient analysis. Ecology 67, 1167-1179.

ter Braak, C.J.F., Verdonschot, P.F.M., 1995. Canonical correspondence analysis and related multivariate methods in aquatic ecology. Aquat. Sci. 57, 255-289. squaloid shark, the Portuguese dogfish (Centroscymnus coelolepis). ICES J. Mar. Sci. 68, 555-563.

Verissimo, A., McDowell, J.R., Graves, J.E., 2012. Genetic population structure and connectivity in a commercially exploited and wide-ranging deepwater shark, the leafscale gulper (Centrophorus squamosus). Mar. Freshwater Res. 63, 505-512.

Ward-Paige, C.A., Keith, D.M., Worm, B., Lotze, H.K., 2012. Recovery potential and conservation options for elasmobranchs. J. Fish. Biol. 80 1844-1869. Mammals: Behaviour Patterns, Mechanisms and Conservation Implications. Adv. Mar. Biol. 54, 107-170.

Wetherbee, B.M., 1996. Distribution and reproduction of the southern lanternshark Etmopterus granulosus from New Zealand . J. Fish. Biol. 49, 1186-1196. Species. Version 2011.1. http://www.iucnredlist.org (accessed $29^{\text {th }}$ September 2011). 
1 Woodhams, J., Vieira, S., Stobutzki, I., 2012. Fishery status reports 2011. Australian Bureau of 2 Agricultural and Resource Economics and Sciences, Canberra.

3 Yano, K., Tanaka, S., 1984. Some biological aspects of the deep-sea squaloid shark

4 Centroscymnus from Suruga Bay, Japan. B. Jpn. Soc. Sci. Fish. 50, 249-256.

5 Yano, K., Tanaka, S., 1988. Size at maturity, reproductive cycle, fecundity and depth

6 segregation of the deep-sea squaloid sharks Centroscymnus owstoni and C. coelolepis in

$7 \quad$ Suruga Bay. Nippon Suisan Gakk. 54, 167-174.

8

\section{Supplementary material}

10 Appendix A. Supplementary material (Tables A1, A2, A3 and A4 and Figures A1, A2, A3, A4, A5 11 and A6)

12 
3 Table 1

4 Portuguese dogfish. Proportion of maturity stages, total numbers by sex ( $\mathrm{n}$ ) and sex-ratio by geographical area and by region (in bold). The immature groups include

5 juveniles. F: females; $M$ : males.

\begin{tabular}{|c|c|c|c|c|c|c|c|c|c|c|}
\hline \multirow{2}{*}{$\begin{array}{l}\text { Portuguese dogfish } \\
\text { Geographical area/region }\end{array}$} & \multicolumn{3}{|c|}{ Males } & \multicolumn{5}{|c|}{ Females } & \multicolumn{2}{|c|}{ Sex ratio } \\
\hline & $\mathbf{n}$ & Immature & Mature & $\mathbf{n}$ & Immature & Mature & Pregnant & Post-natal & F:M & \\
\hline Iceland & 45 & 0.87 & 0.13 & 262 & 0.40 & 0.23 & 0.17 & 0.20 & 5.82 & \\
\hline Rockall \& Hatton Banks & 104 & 0.44 & 0.56 & 669 & 0.42 & 0.23 & 0.00 & 0.34 & 6.43 & 9 \\
\hline Scotland & 136 & 0.51 & 0.49 & 272 & 0.52 & 0.19 & 0.08 & 0.21 & 2.00 & 10 \\
\hline Ireland & 255 & 0.33 & 0.67 & 538 & 0.43 & 0.25 & 0.08 & 0.24 & 2.09 & 11 \\
\hline Bay of Biscay & 39 & 0.10 & 0.90 & 26 & 0.58 & 0.19 & 0.12 & 0.12 & 0.67 & 12 \\
\hline Portugal & 114 & 0.32 & 0.62 & 253 & 0.37 & 0.23 & 0.17 & 0.23 & 2.22 & 13 \\
\hline North Azores (MAR) & 19 & 0.21 & 0.79 & 30 & 0.20 & 0.80 & --- & --- & 1.58 & \\
\hline Canarias Archipelago & 88 & 0.27 & 0.73 & 181 & 0.35 & 0.63 & 0.02 & --- & 2.06 & 14 \\
\hline TOTAL NE ATLANTIC & 800 & 0.39 & 0.61 & 2231 & 0.42 & 0.27 & 0.07 & 0.24 & 2.80 & 15 \\
\hline CE ATLANTIC (Mauritania) & 616 & 1.00 & 0.00 & 765 & 0.98 & 0.01 & 0.01 & --- & 1.24 & 16 \\
\hline SE ATLANTIC (Namibia) & 391 & 0.98 & 0.02 & 553 & 0.99 & 0.01 & --- & --- & 1.41 & 17 \\
\hline NW ATLANTIC (U.S. East Coast) & 21 & 1.00 & --- & 21 & 0.95 & 0.05 & --- & --- & 1.00 & 18 \\
\hline Mozambique Plateau & 229 & 0.60 & 0.40 & 207 & 0.34 & 0.57 & 0.09 & --- & 0.90 & \\
\hline Madagascar Plateau & 72 & 0.39 & 0.61 & 34 & 0.32 & 0.38 & 0.29 & --- & 0.47 & 19 \\
\hline TOTAL SW INDIAN & 301 & 0.55 & 0.45 & 241 & 0.34 & 0.54 & 0.12 & --- & 0.80 & 20 \\
\hline New South Wales & 62 & 0.68 & 0.32 & 23 & 0.65 & 0.09 & 0.09 & 0.17 & 0.37 & 21 \\
\hline Tasmania & 171 & 0.09 & 0.71 & 70 & 0.51 & 0.17 & 0.16 & 0.16 & 0.41 & 22 \\
\hline TOTAL SW PACIFIC & 233 & 0.25 & 0.75 & 93 & 0.55 & 0.15 & 0.14 & 0.16 & 0.40 & 23 \\
\hline
\end{tabular}


Table 2

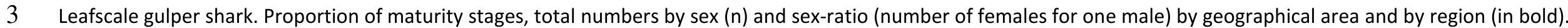

4 The immature groups include juveniles. F: females; M: males.

\begin{tabular}{|c|c|c|c|c|c|c|c|c|c|c|}
\hline \multirow{2}{*}{$\begin{array}{l}\text { Leafscale gulper shark } \\
\text { Geographical area/region }\end{array}$} & \multicolumn{3}{|l|}{ Males } & \multicolumn{5}{|c|}{ Females } & \multicolumn{2}{|c|}{ Sex ratio } \\
\hline & $\mathrm{n}$ & Immature & Mature & $\mathrm{n}$ & Immature & Mature & Pregnant & Post-natal & $\mathrm{F}: \mathrm{M}$ & 6 \\
\hline Iceland & 10 & 0.80 & 0.20 & 36 & 0.22 & 0.28 & 0.14 & 0.36 & 3.60 & 7 \\
\hline Rockall \& Hatton Banks & 352 & 0.28 & 0.72 & 275 & 0.90 & 0.04 & --- & 0.06 & 0.78 & 7 \\
\hline Scotland & 308 & 0.25 & 0.75 & 405 & 0.82 & 0.10 & --- & 0.08 & 1.31 & 8 \\
\hline Ireland & 322 & 0.39 & 0.61 & 248 & 0.95 & 0.04 & --- & 0.01 & 0.77 & \\
\hline Portugal & 133 & 0.25 & 0.75 & 122 & 0.81 & 0.09 & 0.02 & 0.07 & 0.92 & 9 \\
\hline North Azores (MAR) & 82 & --- & 1.00 & 1 & 1.00 & --- & --- & --- & 0.01 & 10 \\
\hline Madeira Archipelago & 145 & 0.06 & 0.94 & 60 & 0.42 & 0.08 & 0.50 & --- & 0.41 & 10 \\
\hline Canarias Archipelago & 31 & 0.48 & 0.52 & 43 & 0.42 & 0.58 & --- & --- & 1.39 & 11 \\
\hline TOTAL NE ATLANTIC & 1383 & 0.27 & 0.73 & 1190 & 0.81 & 0.09 & 0.03 & 0.06 & 0.86 & 12 \\
\hline CE ATLANTIC (Mauritania) & 42 & 0.76 & 0.19 & 44 & 1.00 & --- & --- & --- & 1.04 & \\
\hline Chatham Rise \& North Island & 134 & 0.87 & 0.13 & 273 & 0.81 & 0.16 & 0.03 & 0.01 & 2.04 & 13 \\
\hline South Island, Campbell Plateau & 182 & 0.58 & 0.42 & 235 & 0.74 & 0.23 & 0.02 & 0.01 & 1.29 & 14 \\
\hline TOTAL SW PACIFIC & 316 & 0.70 & 0.30 & 508 & 0.78 & 0.19 & 0.02 & 0.01 & 1.61 & 15 \\
\hline
\end{tabular}




\section{Table 3}

Birdbeak dogfish. Proportion of maturity stages, total numbers by sex ( $\mathrm{n}$ ) and sex-ratio by geographical area and by region (in bold). The immature groups include juveniles.

4 F: females; M: males.

\begin{tabular}{|c|c|c|c|c|c|c|c|c|c|c|}
\hline \multirow{2}{*}{$\begin{array}{l}\text { Birdbeak dogfish } \\
\text { Geographical area/Region }\end{array}$} & \multicolumn{3}{|l|}{ Males } & \multicolumn{5}{|c|}{ Females } & \multicolumn{2}{|c|}{ Sex ratiø } \\
\hline & $\mathrm{n}$ & Immature & Mature & n & Immature & Mature & Pregnant & Post-natal & $\mathrm{F}: \mathrm{M}$ & 7 \\
\hline Iceland & 151 & 0.19 & 0.81 & 100 & 0.55 & 0.24 & 0.04 & 0.17 & 0.66 & $\begin{array}{l}9 \\
0\end{array}$ \\
\hline Scotland & 218 & 0.51 & 0.49 & 112 & 0.79 & 0.06 & 0.01 & 0.13 & 0.51 & $\begin{array}{r}9 \\
10\end{array}$ \\
\hline Ireland & 901 & 0.48 & 0.52 & 602 & 0.83 & 0.10 & 0.02 & 0.05 & 0.67 & 11 \\
\hline Rockall \& Hatton Banks & 248 & 0.21 & 0.79 & 129 & 0.76 & 0.10 & --- & 0.14 & 0.52 & 12 \\
\hline Bay of Biscay & 66 & 0.12 & 0.88 & 100 & 0.85 & 0.14 & 0.01 & --- & 1.52 & 13 \\
\hline Portugal & 0 & --- & -- & 33 & 0.76 & 0.18 & 0.06 & --- & --- & 14 \\
\hline TOTAL NE ATLANTIC & 1589 & 0.40 & 0.60 & 1122 & 0.77 & 0.14 & 0.02 & 0.07 & 0.71 & 17 \\
\hline CE ATLANTIC (Mauritania) & 542 & 0.93 & 0.07 & 722 & 0.90 & 0.06 & 0.02 & 0.00 & 1.33 & 18 \\
\hline SE ATLANTIC (Namibia) & 211 & 0.55 & 0.45 & 113 & 0.53 & 0.47 & -- & --- & 0.53 & 19 \\
\hline Chatham Rise \& North Island & 3548 & 0.37 & 0.63 & 3960 & 0.78 & 0.05 & 0.02 & 0.16 & 1.12 & 20 \\
\hline South Island, Campbell Plateau & 195 & 0.12 & 0.88 & 187 & 0.83 & 0.17 & --- & --- & 0.96 & 21 \\
\hline TOTAL SW PACIFIC & 3743 & 0.36 & 0.64 & 4147 & 0.78 & 0.05 & 0.02 & 0.15 & 1.11 & 22 \\
\hline
\end{tabular}




\section{Figure legends}

Fig. 1. Worldwide sampling sites for the Portuguese dogfish, leafscale gulper shark and birdbeak dogfish. NW Atlantic, including (a) Gulf of Mexico; (b) U.S. East Coast; and (c) Greenland. NE Atlantic including (d) Iceland; (e) Rockall and Hatton Banks; (f) Scotland; (g) North of the Charlie-Gibbs Fracture Zone; (h) Ireland; (i) north Azores; (j) Bay of Biscay; (k) Portugal; (I) south Azores; (m) Madeira Archipelago; and (n) Canarias Archipelago. CE Atlantic in particular (o) Mauritania. SE Atlantic in particular (p) Namibia. SW Indian including (q) Mozambique Plateau; and (r) Madagascar Plateau. SW Pacific including (s) New South Wales;

(t) Tasmania (Australia). (u) Chatham Rise and North Island; and (v) South Island and Campbell Plateau (New Zealand).

Fig. 2. Relationship between the sampling depth and maturity stage by region for the Portuguese dogfish, leafscale gulper shark and birdbeak dogfish ( $n=16042)$. In the box-andwhisker plots, the box represents the 25th and 75th quantiles. The whiskers represent 1.5 times the interquartile range. The points beyond the whiskers are potential outliers. The black dots represent the medians. JV: juveniles; IM: immatures; MM: mature males; MF: mature females; PG: pregnant females; PN: post-natal females. Empty cells represent a lack of sampling data for the respective species and not necessarily that the species doesn't occur.

Fig. 3. Portuguese dogfish. Occurrences of (a) juveniles, (b) mature males and females, and (c) pregnant and post-natal females in the NE Atlantic. 
Fig. 4. Constrained correspondence analysis of the Portuguese dogfish distribution by maturity stage. Ordination of the maturity stages (black circles) and hauls (grey circles) overlaid with the surface model fitted for depth (in metres) in the NE Atlantic ( $n=2991 ; 509$ hauls). Axes 1 accounted for $100 \%$ of the variance of the fitted values.

Fig. 5. Leafscale gulper shark. Occurrences of (a) juveniles, (b) mature males and females; (c) pregnant and post-natal females in the NE Atlantic; of (d) juveniles, (e) mature males and females; (f) pregnant and post-natal females in the SW Pacific (New Zealand).

Fig. 6. Constrained correspondence analysis of leafscale gulper shark distribution by maturity stage. Ordination of the maturity stages (black circles) and hauls (grey circles) overlaid with the surface model fitted for (a) depth (in metres) and (b) temperature (in ${ }^{\circ} \mathrm{C}$ ) in the NE Atlantic ( $\mathrm{n}=$ 2435; 374 hauls) and for (c), depth and (d), salinity in the SW Pacific (New Zealand; $n=808 ; 241$ hauls). In the NE Atlantic data axes 1 and 2 accounted for $63 \%$ and $37 \%$ of the variance of the fitted values, respectively whereas in the SW Pacific axes 1 and 2 accounted for $97 \%$ and $3 \%$ of the variance of the fitted values, respectively.

Fig. 7. Birdbeak dogfish. Occurrences of (a) juveniles, (b) mature males and females; (c) pregnant and post-natal females in the NE Atlantic; of (d) juveniles, (e) mature males and females; (f) pregnant and post-natal females in the CE Atlantic (Mauritania); of (g) juveniles, (h) mature males and females; (i) pregnant and post-natal females in the SW Pacific (New Zealand). 
Fig. 8. Constrained correspondence analysis of birdbeak dogfish distribution by maturity stage. Ordination of the maturity stages (black circles) and hauls (grey circles) overlaid with the surface model fitted for (a) depth in the NE Atlantic ( $n=2672 ; 310$ hauls) for (b) depth (in metres) and (c) salinity (in PSU) in the SW Pacific (New Zealand, $n=7508 ; 445$ hauls). In the NE Atlantic analysis axis 1 accounted for $100 \%$ of the variance of the fitted values whereas in the SW Pacific axis 1 and 2 accounted for $61 \%$ and $39 \%$ of the variance of the fitted values, respectively. 

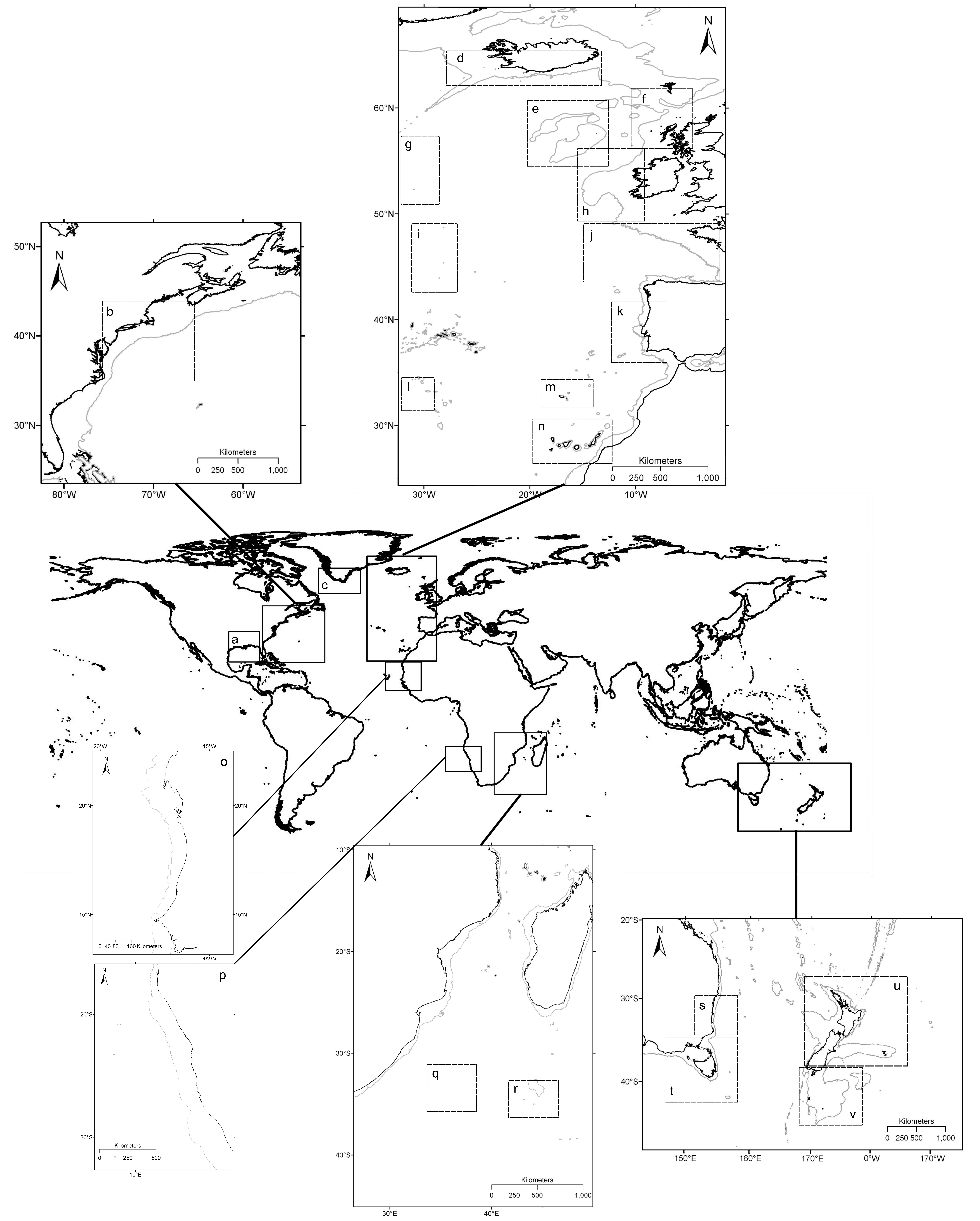


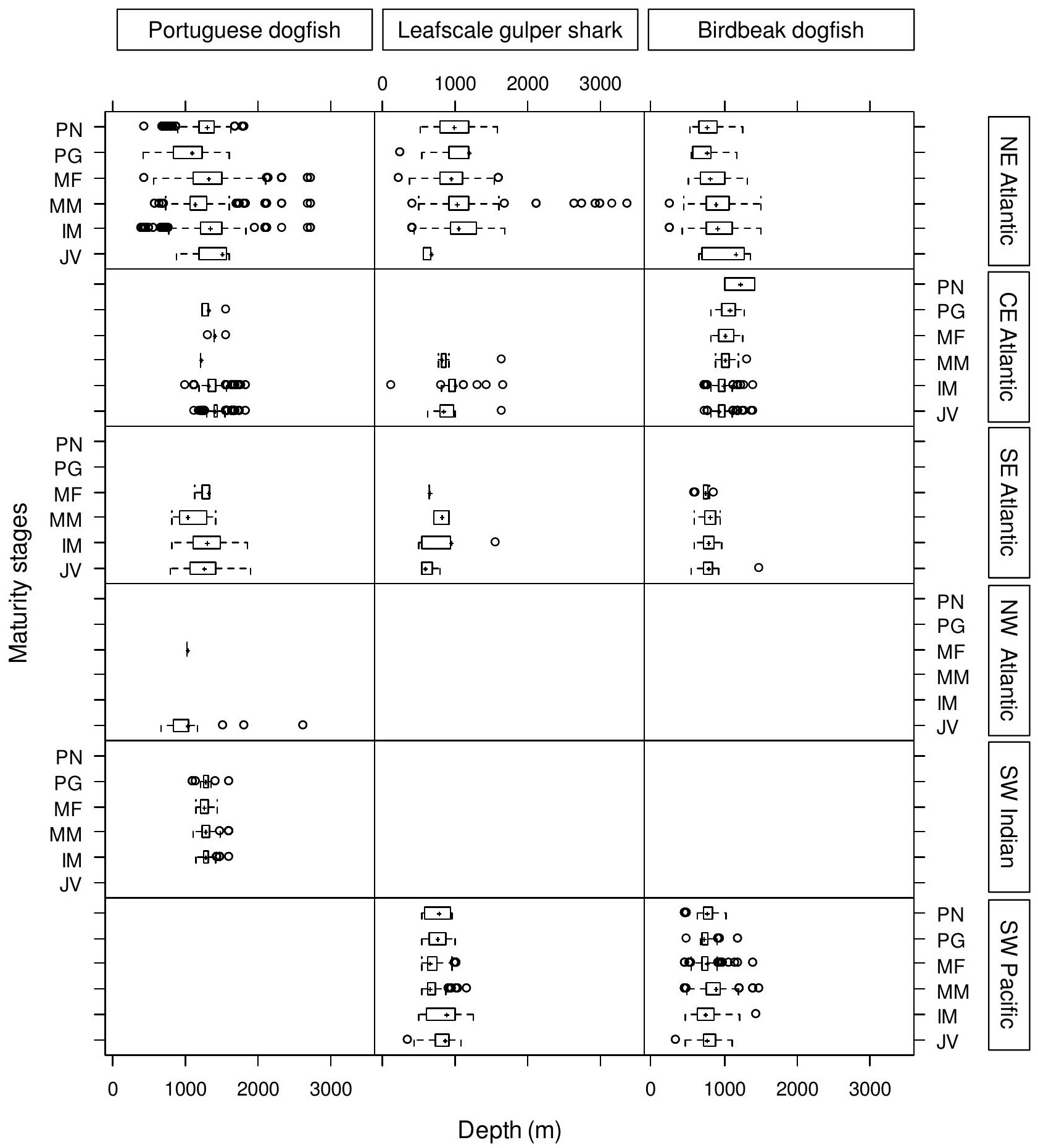



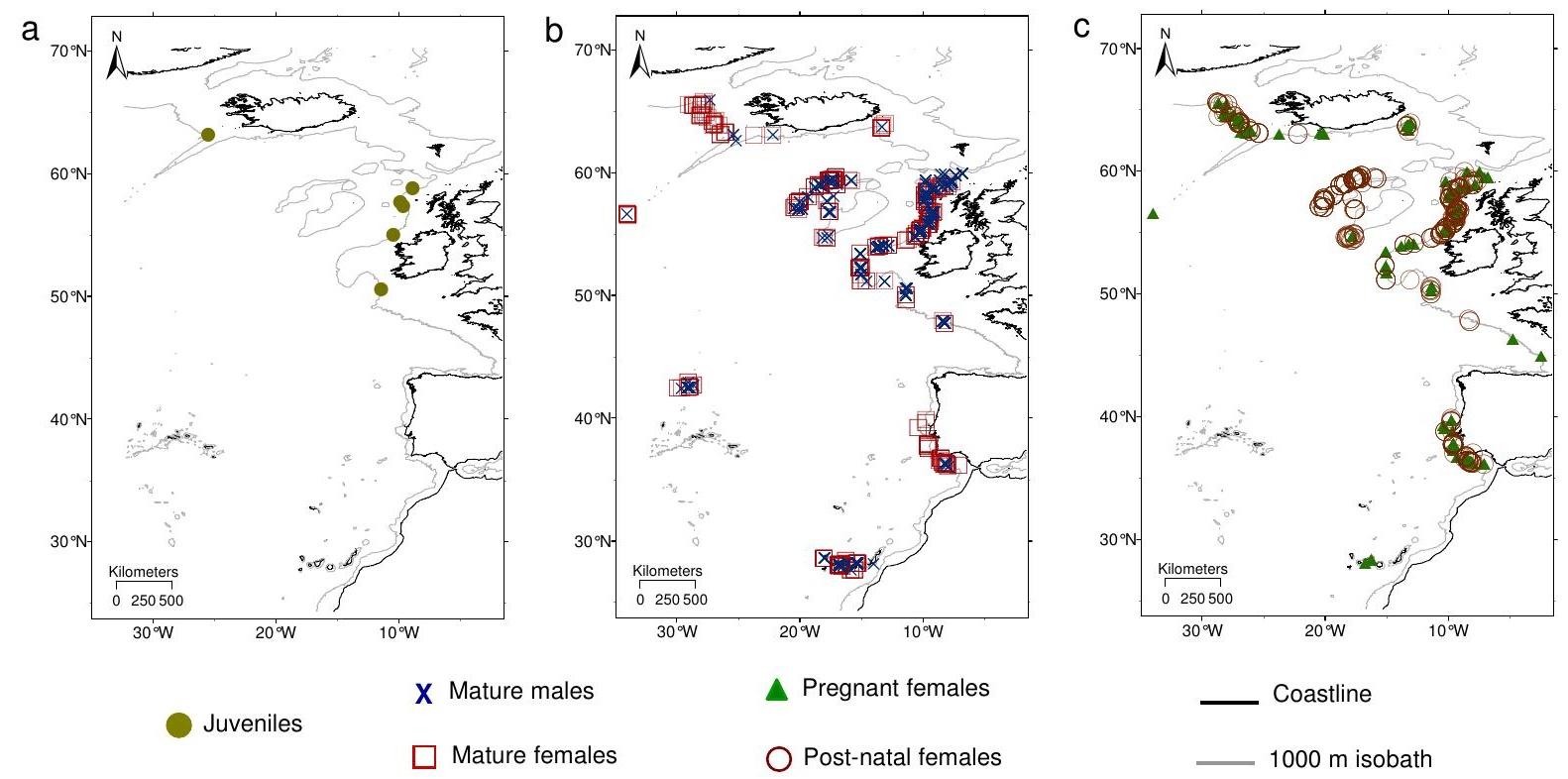

$1000 \mathrm{~m}$ isobath 

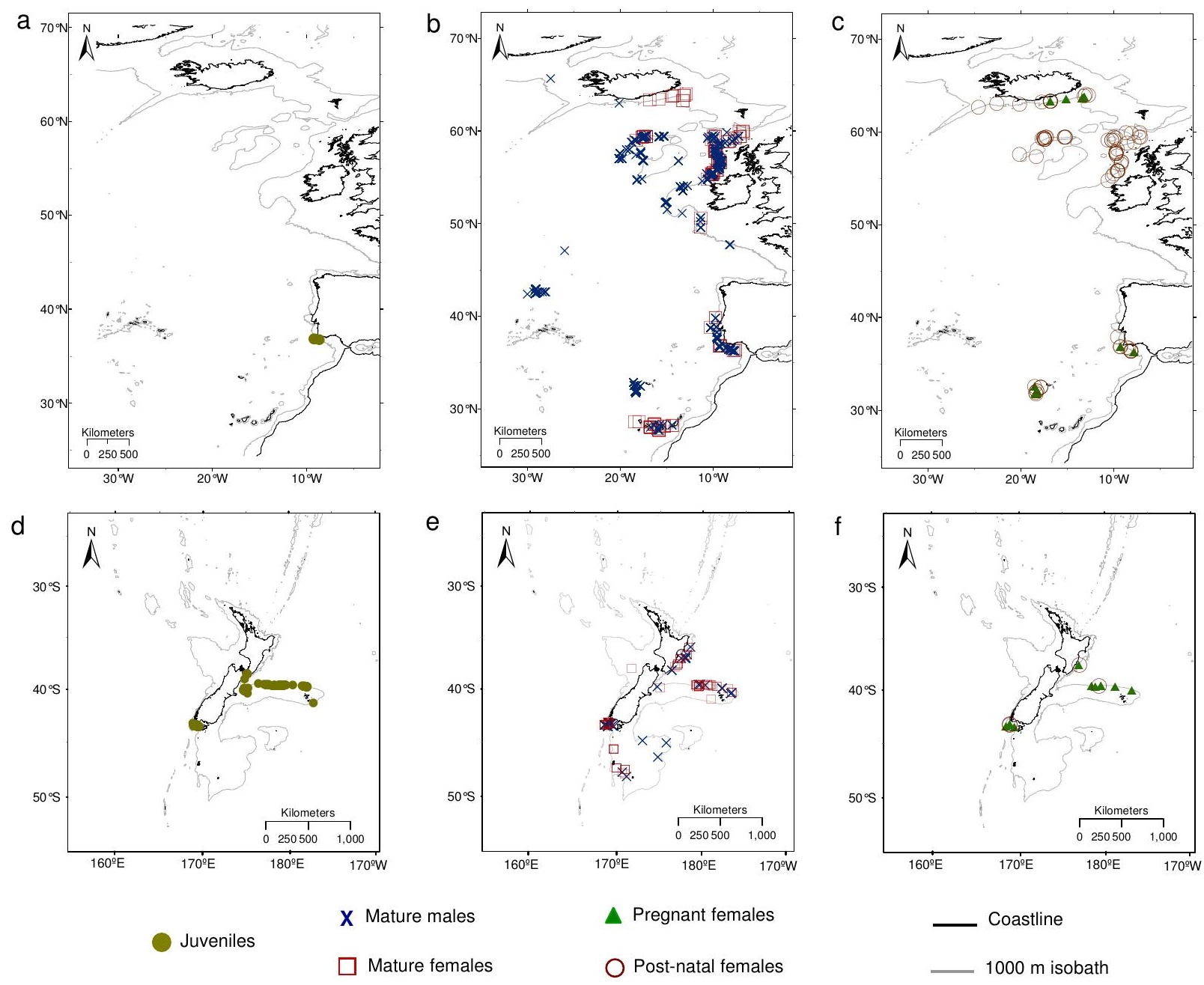
a

Leafscale gulper shark, NE Atlantic

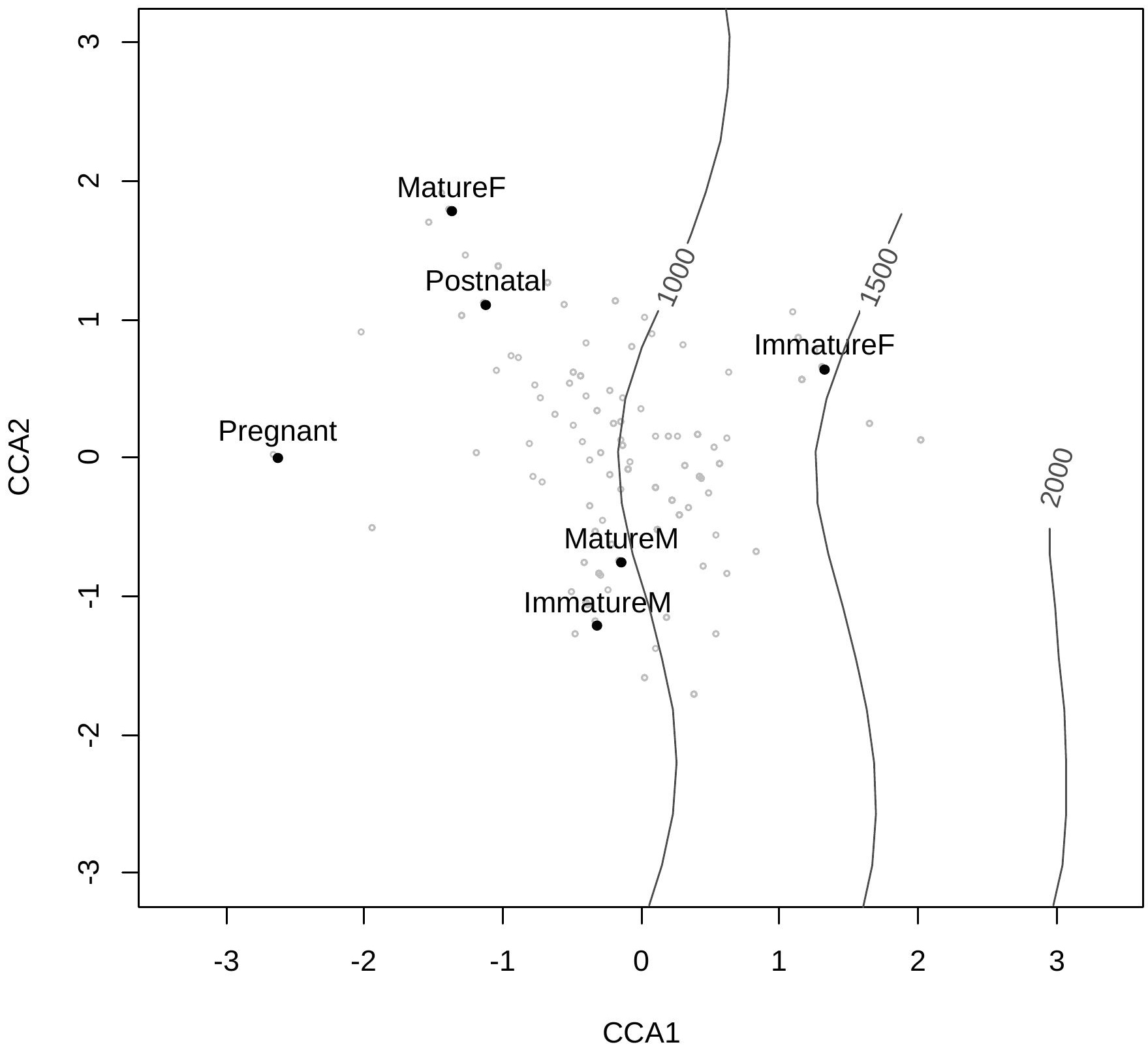

C

\section{Leafscale gulper shark, SW Pacific}

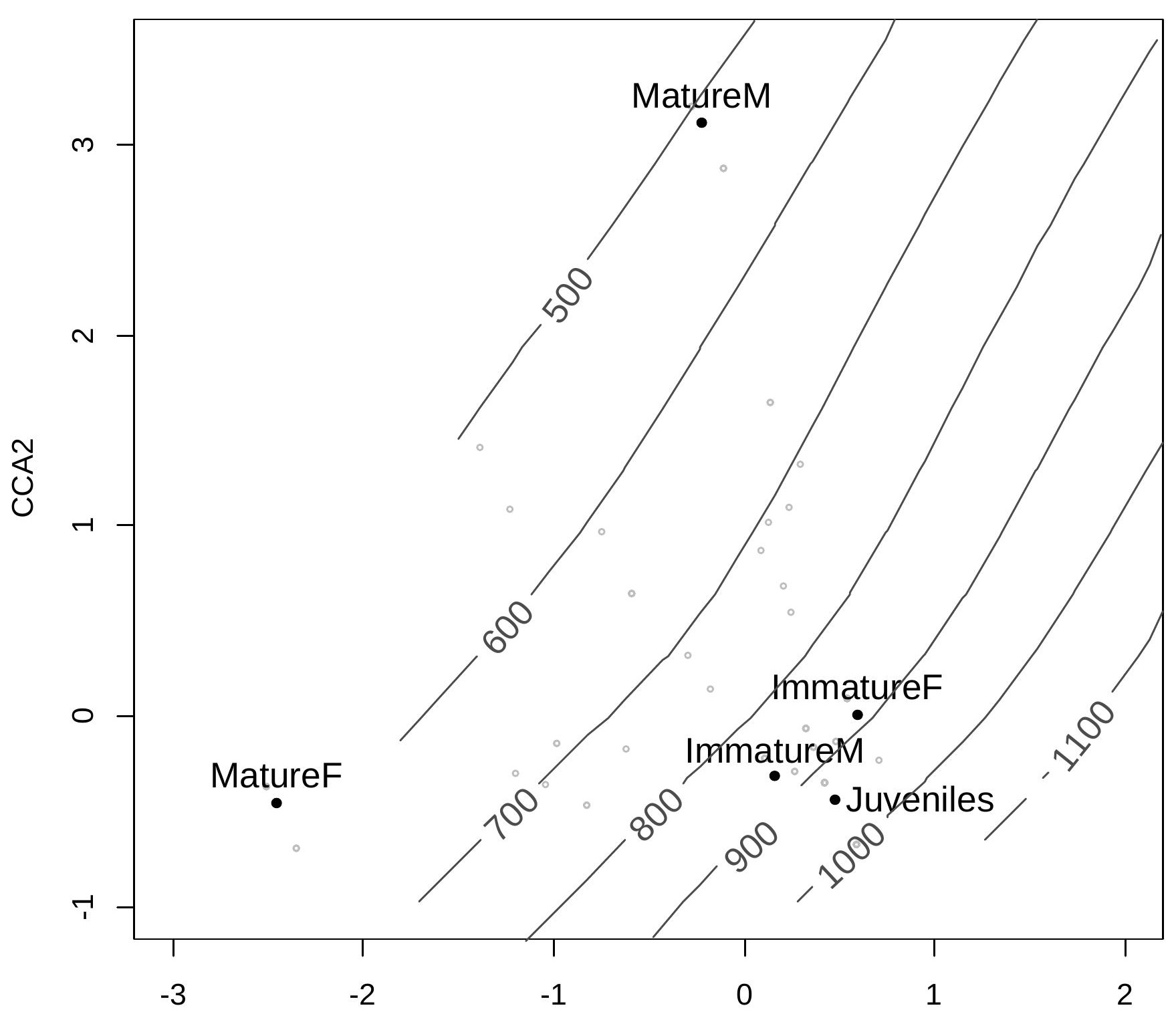

b

\section{Leafscale gulper shark, NE Atlantic}

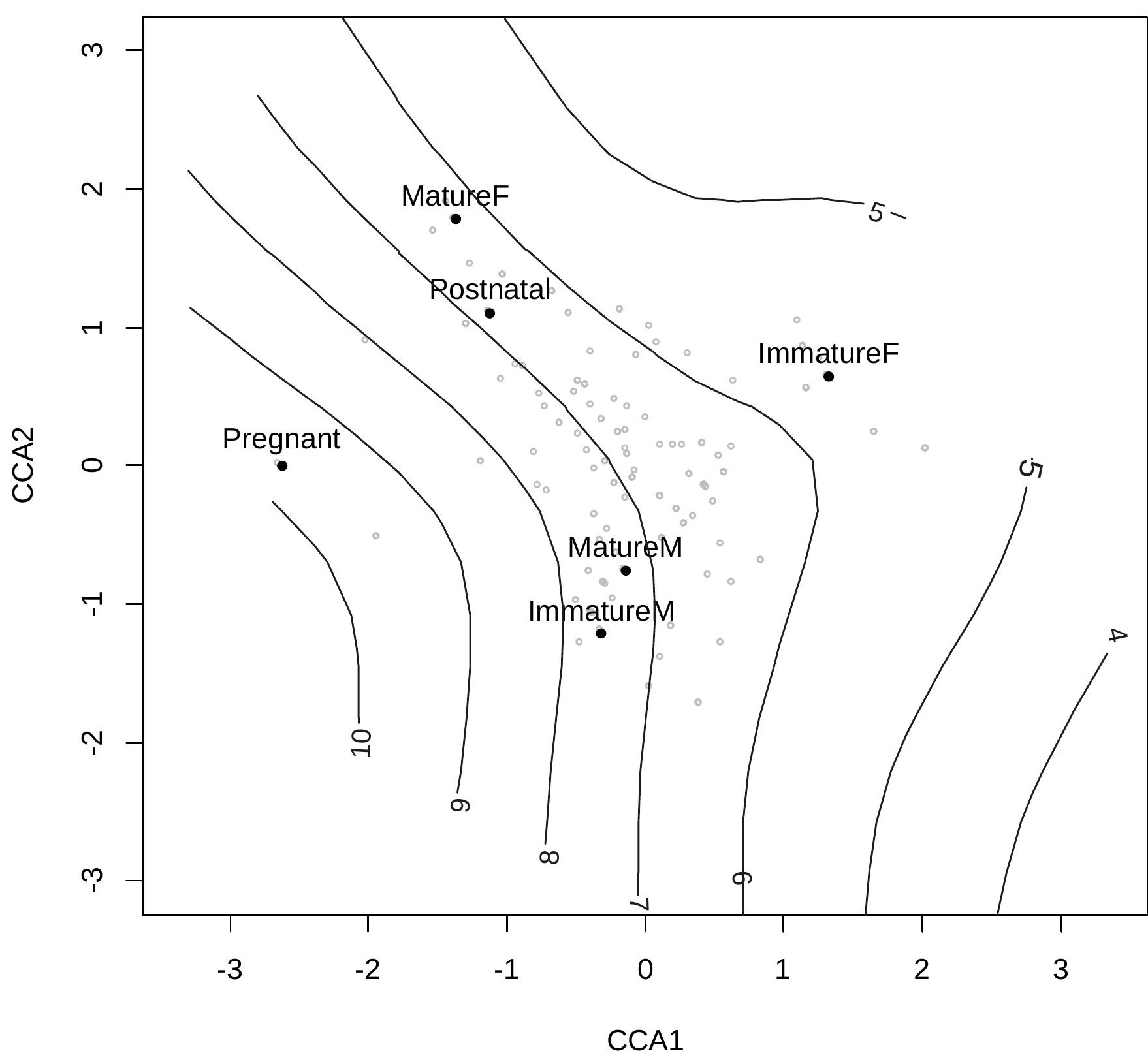

d

\section{Leafscale gulper shark, SW Pacific}

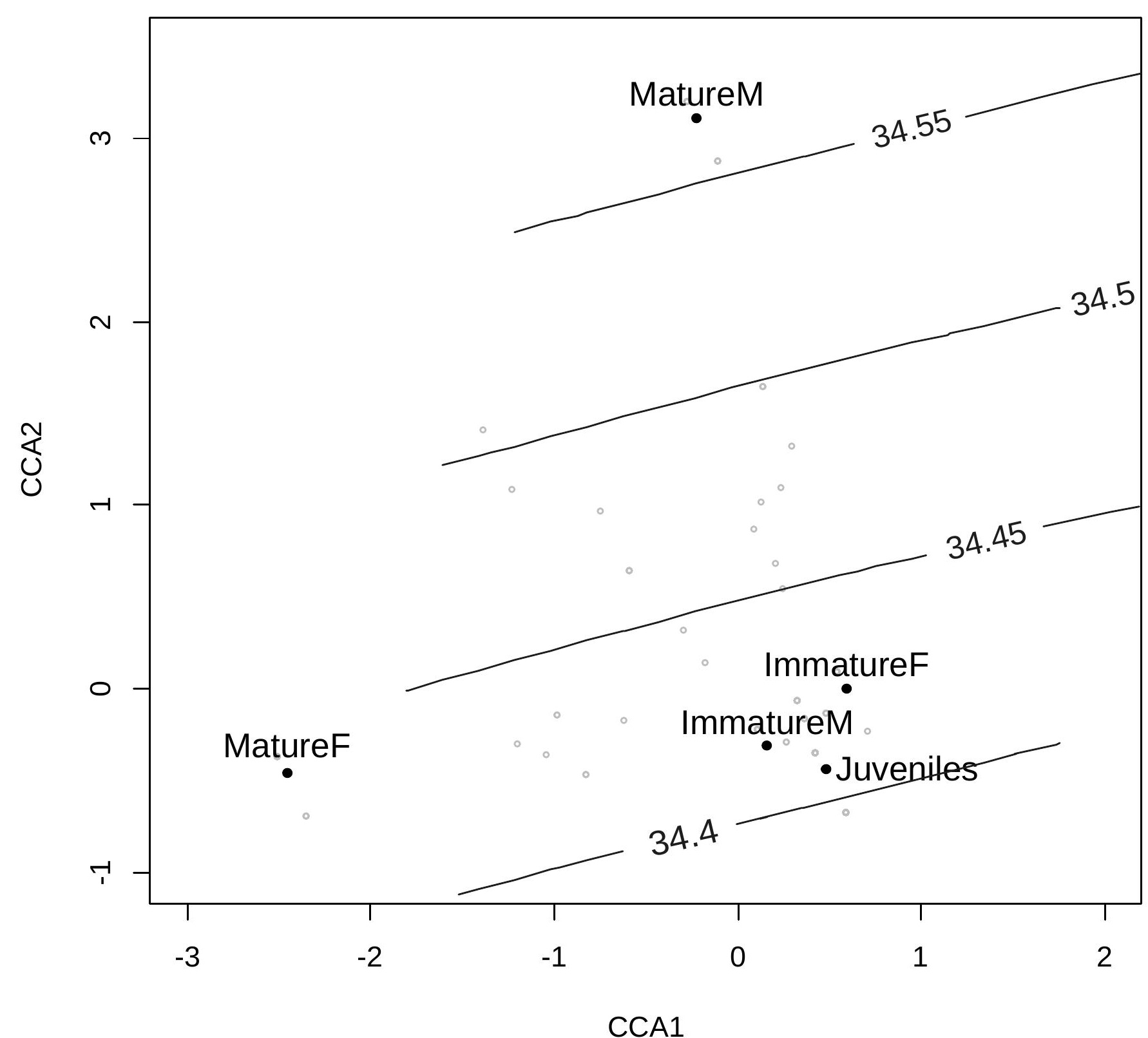



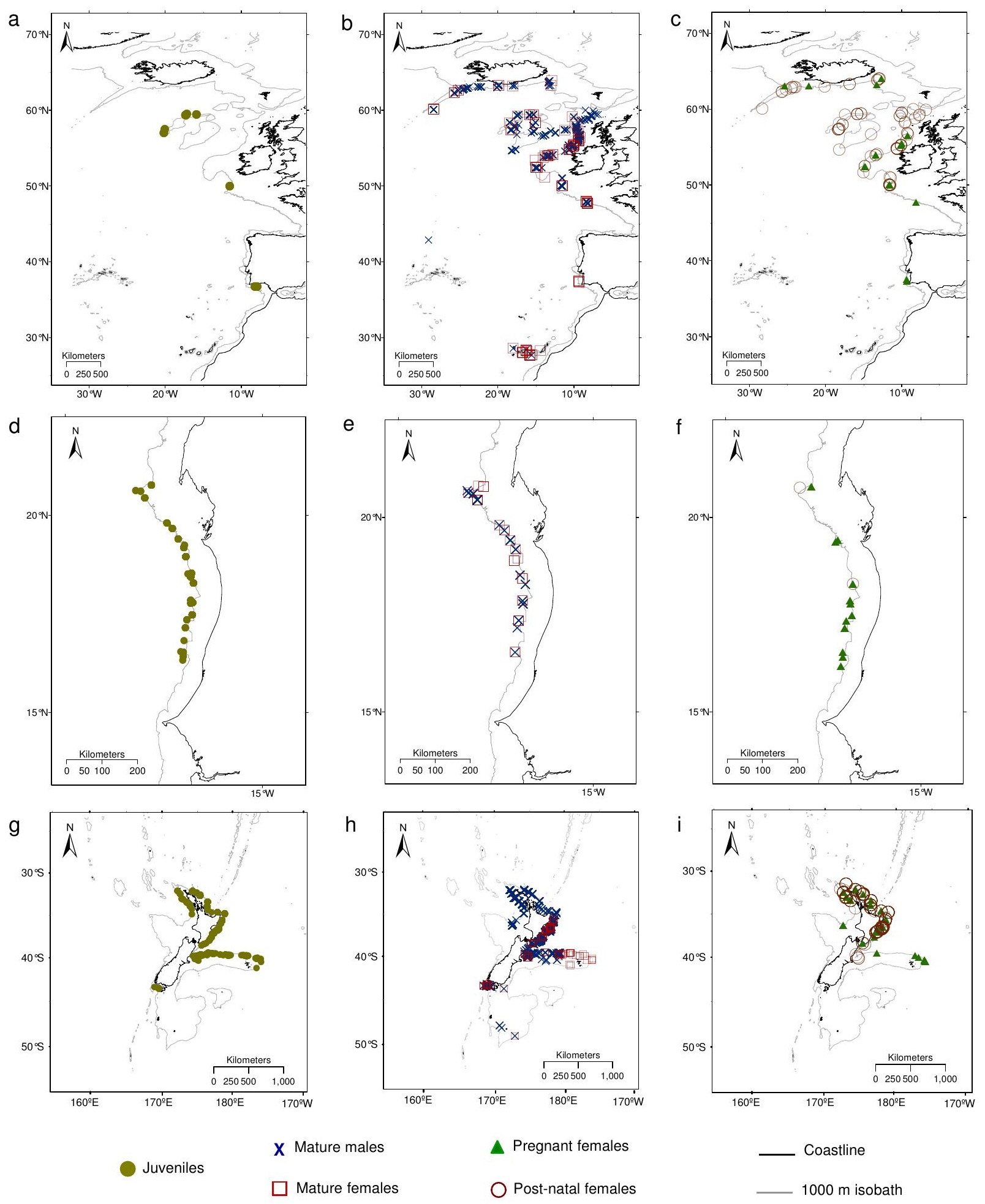


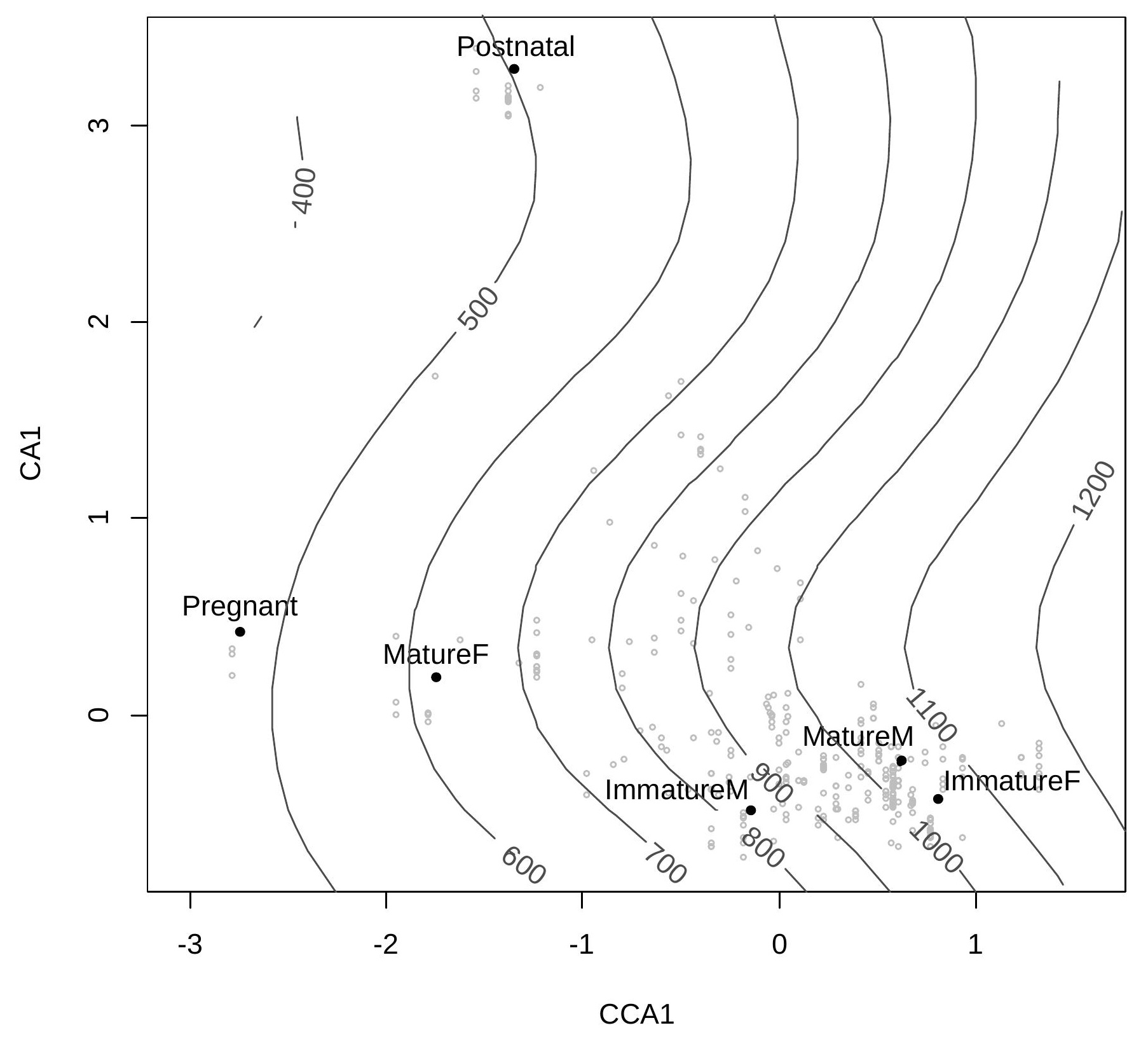

b

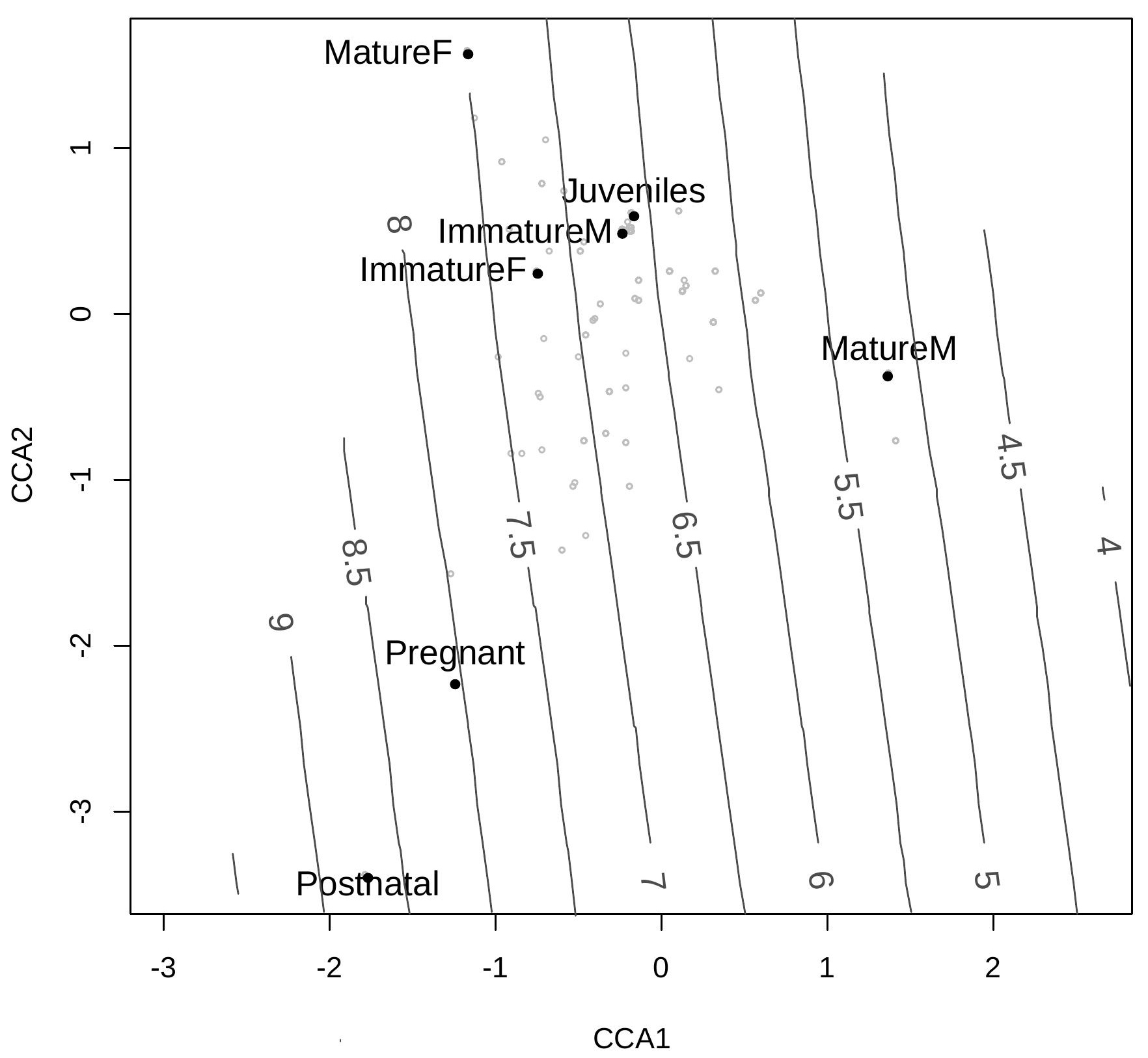

C

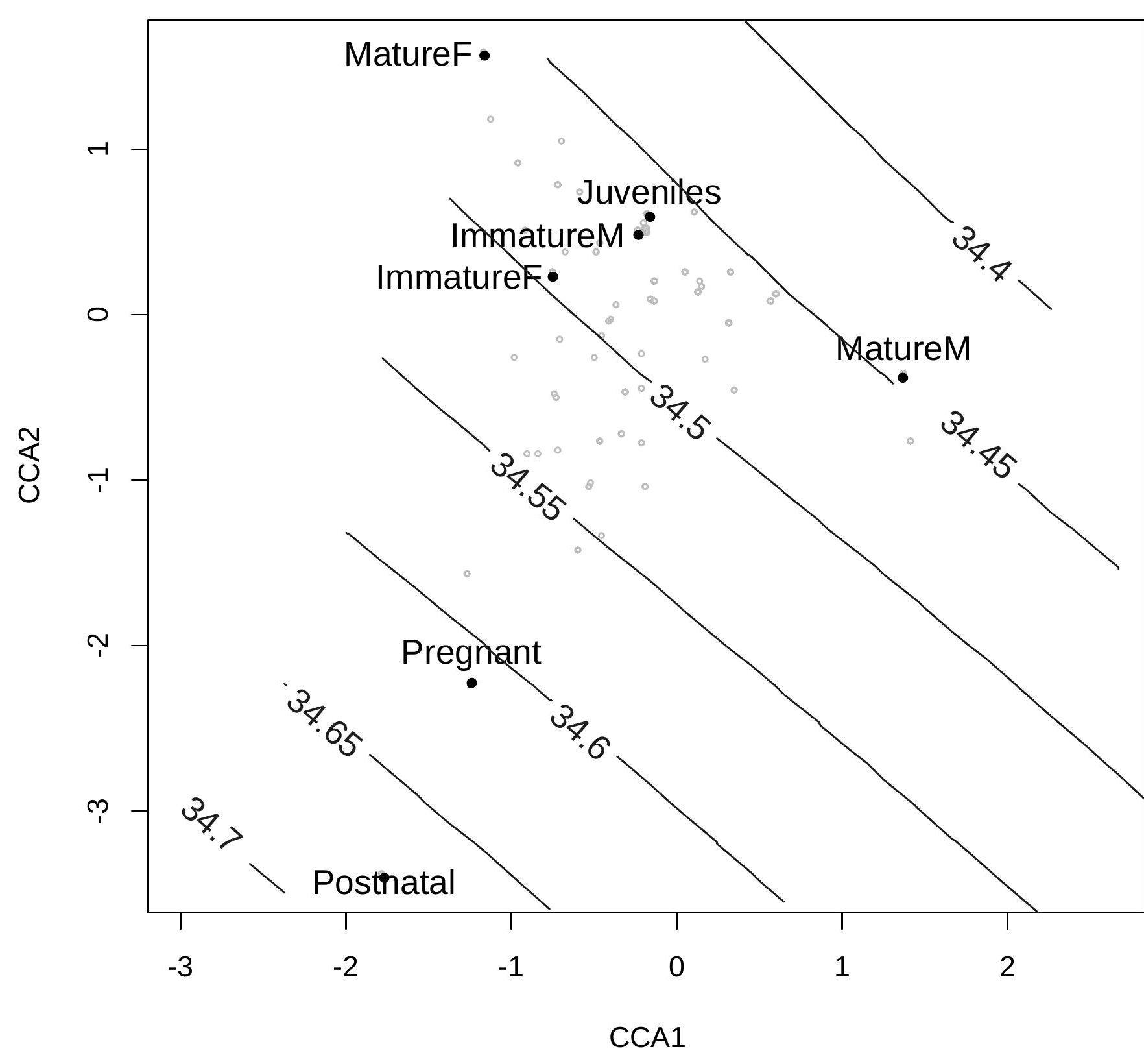


Table A1

Identification of the datasets available for the Portuguese dogfish (PD), leafscale gulper shark (LGS) and birdbeak dogfish (BD). Region: NE, northeast; CE, center-east, SE, southeast, NW,

northwest; SW, southwest. Geographical area: CGFZ, Charlie-Gibbs Fracture Zone. Data source: Comm., sampling of commercial catches; Res. Surv., research survey; Trial Fish., trial fisheries.

\begin{tabular}{|c|c|c|c|c|c|c|c|c|}
\hline Region & Geographical area & $\mathrm{R} / \mathrm{V}$ or Project/ sampling port & $\begin{array}{c}\text { Data } \\
\text { source }\end{array}$ & Gear & Period & PD & LGS & BD \\
\hline \multirow[t]{17}{*}{ NE ATLANTIC } & Greenland & F/V Skarheim, Husøy & Trial Fish. & Longline & 1993,1995 & $\checkmark$ & & \\
\hline & Iceland & Autumn Groundfish Survey & Res.Surv. & Trawl & $1996-2010$ & $\checkmark$ & $\checkmark$ & $\checkmark$ \\
\hline & Iceland: Reykjanes Ridge & F/V Borgarin & Trial Fish. & Longline & 1996 & $\checkmark$ & & $\checkmark$ \\
\hline & Mid-Atlantic Ridge: North CGFZ & F/V Skarheim & Trial Fish. & Longline & 1997 & $\checkmark$ & & \\
\hline & West of Scotland, Ireland & R/V Scotia & Res.Surv. & Trawl & $2000,2005-2008$ & $\checkmark$ & $\checkmark$ & $\checkmark$ \\
\hline & Ireland, West of Scotland & F/V Mary M & Res.Surv. & Trawl & 1996-1999 & $\checkmark$ & $\checkmark$ & $\checkmark$ \\
\hline & Hatton Bank, Rockall Bank & R/V Koralnes & Res.Surv. & Trawl & 1998 & $\checkmark$ & $\checkmark$ & $\checkmark$ \\
\hline & Ireland, Hatton Bank, Rockall Bank & MS Loran & Res.Surv. & Longline & $1996,1999-2000$ & $\checkmark$ & $\checkmark$ & $\checkmark$ \\
\hline & Bay of Biscay (West Brittany), West of Scotland, Ireland & R/V Thalassa & Res.Surv. & Trawl & 1999 & $\checkmark$ & $\checkmark$ & $\checkmark$ \\
\hline & Bay of Biscay (West Brittany), Rockall and Hatton Banks & Lochinver port, W Scotland & Comm. & Trawl & $2000-2001$ & $\checkmark$ & $\checkmark$ & $\checkmark$ \\
\hline & Bay of Biscay (Cantabrian Sea) & Ondarroa port, Basque Country & Comm. & Longline & 2001-2002 & $\checkmark$ & $\checkmark$ & $\checkmark$ \\
\hline & Portugal & Profundidade, R/V Noruega & Res.Surv. & Trawl/Longline & $1994-95,1997,2003$ & & $\checkmark$ & $\checkmark$ \\
\hline & Portugal & TUBAPROF, Sesimbra port & Comm. & Longline & $2006-2007$ & $\checkmark$ & $\checkmark$ & \\
\hline & Mid-Atlantic Ridge: north and south Azores & MS Loran & Res.Surv. & Longline & 1996, 2004 & $\checkmark$ & $\checkmark$ & $\checkmark$ \\
\hline & Madeira Archipelago & Funchal port & Comm. & Longline & 2004 & & $\checkmark$ & \\
\hline & Canarias Archipelago & MARE, R/V G. W. Pierce II & Res.Surv. & Longline & 1986 & $\checkmark$ & & $\checkmark$ \\
\hline & Canarias Archipelago & Experimental fishing & Res.Surv.. & Longline & 1991-1999, 2010 & $\checkmark$ & $\checkmark$ & $\checkmark$ \\
\hline CE ATLANTIC & Mauritania & R/V Vizconde de Eza & Res.Surv. & Trawl & $2007-2008$ & $\checkmark$ & $\checkmark$ & $\checkmark$ \\
\hline SE ATLANTIC & Namibia & R/V Vizconde de Eza & Res.Surv. & Trawl & 2006-2007 & $\checkmark$ & $\checkmark$ & $\checkmark$ \\
\hline \multirow[t]{2}{*}{ NW ATLANTIC } & USA East Coast & Multiple VIMS Research Surveys & Res.Surv. & Trawl/ Traps & 1973-1979 & $\checkmark$ & & $\checkmark$ \\
\hline & Gulf of Mexico & FSU BP-11 cruise, R/V Weatherbird II & Res.Surv. & Longline & 2011 & & & $\checkmark$ \\
\hline SW INDIAN & Mozambique Plateau, Madagascar Plateau & Experimental fishing & Comm. & Longline & 2004 & $\checkmark$ & & \\
\hline \multirow[t]{3}{*}{ SW PACIFIC } & New South Wales, Tasmania (Australia) & Several $\mathrm{F} / \mathrm{V}$ and ports & Comm. & Trawl & $1986-2002$ & $\checkmark$ & & \\
\hline & North Island, Challenger Plateau (New Zealand) & F/V Wanaka & Res.Surv. & Trawl & 1985-1986 & & & $\checkmark$ \\
\hline & $\begin{array}{l}\text { North Island, South Island, Chatham Rise, Campbell Plateau } \\
\text { (New Zealand) }\end{array}$ & R/V Tangaroa & Res.Surv. & Trawl & $1996-2010$ & $\checkmark$ & $\checkmark$ & $\checkmark$ \\
\hline
\end{tabular}




\section{Table A2}

Compiled data available for the Portuguese dogfish by region and geographical Area. Data presented includes the number of sampled specimens ( $\mathrm{n}$ ), total length range (TL, in $\mathrm{cm}$ ) by sex and depth range of capture (in $\mathrm{m}$ ) for all the specimens; the number ( $\mathrm{n}$ ), total length range (TL, in $\mathrm{cm}$ ) and depth range of capture (in $\mathrm{m}$ ) of all the sampled juveniles; the number of specimens used in the analysis $(n)$ and the analysis carried out for each geographical area. Since there were some gaps for some variables in the datasets the number of sampled specimens might differ between analyses. CCA: constrained correspondence analysis; CGFZ: Charlie-Gibbs Fracture Zone; MAR: Mid-

Atlantic Ridge; NA: information not available.

\begin{tabular}{|c|c|c|c|c|c|c|c|c|c|c|c|c|}
\hline \multirow[b]{2}{*}{ Region } & \multirow[b]{2}{*}{ Geographical Area } & \multicolumn{3}{|c|}{ All specimens } & \multirow[b]{2}{*}{$\begin{array}{l}\text { Depth } \\
\text { range }(\mathrm{m})\end{array}$} & \multicolumn{3}{|c|}{ Juveniles information } & \multicolumn{2}{|c|}{ Analysis information } & \multirow[b]{2}{*}{$\begin{array}{l}\text { Sex } \\
\text { ratio }\end{array}$} & \multirow[b]{2}{*}{ CCA } \\
\hline & & $\mathbf{n}$ & $\begin{array}{l}\text { Males TL } \\
\text { range } \\
(\mathrm{cm})\end{array}$ & $\begin{array}{l}\text { Females } \\
\text { TL range } \\
(\mathrm{cm})\end{array}$ & & $\mathbf{n}$ & $\begin{array}{l}\mathrm{TL} \\
\text { range }\end{array}$ & $\begin{array}{l}\text { Depth } \\
\text { range }(\mathrm{m})\end{array}$ & notes & $\mathbf{n}$ & & \\
\hline \multirow[t]{10}{*}{ NE ATLANTIC } & Greenland & 21 & 89 & $83-114$ & $840-1247$ & 1 & 58 & 1213 & $a, b$ & & & \\
\hline & Iceland & 311 & $62-112$ & $49-120$ & $407-1404$ & 1 & 49 & 880 & & 307 & $*$ & $*$ \\
\hline & Rockall \& Hatton Banks & 2556 & $66-117$ & $72-130$ & $627-1930$ & & & & $c, b$ & 773 & $*$ & $*$ \\
\hline & Scotland & 408 & $31-109$ & $37-126$ & $416-1800$ & 4 & $31-58$ & 1500 & & 408 & $*$ & $*$ \\
\hline & Ireland & 931 & $70-114$ & $37-130$ & $562-1823$ & 1 & 37 & 1600 & $c, b$ & 793 & $*$ & $*$ \\
\hline & Bay of Biscay & 80 & $78-99$ & $84-113$ & 1151-1947 & & & & & 65 & $*$ & $*$ \\
\hline & Portugal & 367 & $69-99$ & $73-118$ & $1119-1640$ & & & & & 367 & $*$ & $*$ \\
\hline & North CGFZ (MAR) & 44 & $59-97$ & $102-122$ & $566-866$ & & & & $d$ & & & \\
\hline & North Azores (MAR) & 64 & $81-101$ & $85-121$ & 883-1929 & & & & & 49 & $*$ & $*$ \\
\hline & Canarias Archipelago & 295 & $71-100$ & $67-125$ & $750-2715$ & & & & & 269 & $*$ & $*$ \\
\hline CE ATLANTIC & Mauritania & 1381 & $32-92$ & $30-123$ & $1006-1835$ & 796 & $30-60$ & $1006-1835$ & e & 1381 & $*$ & \\
\hline SE ATLANTIC & Namibia & 944 & $33-100$ & $28-110$ & $798-1882$ & 695 & $28-60$ & $798-1882$ & $\mathrm{e}$ & 944 & $*$ & \\
\hline NW ATLANTIC & U.S. East Coast & 62 & $32-47$ & $30-123$ & $670-2624$ & 53 & $37-49$ & $670-2624$ & $b, e$ & 42 & & \\
\hline \multirow[t]{2}{*}{ SW INDIAN } & Mozambique Plateau & 1400 & $69-126$ & $79-118$ & $1007-1481$ & & & & & 436 & $*$ & (f) \\
\hline & Madagascar Plateau & 106 & $69-120$ & $72-121$ & $1112-1606$ & & & & & 106 & $*$ & (f) \\
\hline \multirow[t]{3}{*}{ SW PACIFIC } & New South Wales (Australia) & 85 & $48-98$ & $55-110$ & NA & 8 & $48-58$ & NA & g & 85 & (g) & (g) \\
\hline & Tasmania (Australia) & 241 & $67-122$ & $72-120$ & NA & & & & g & 241 & (g) & (g) \\
\hline & $\begin{array}{l}\text { North Island \& Challenger Plateau (New } \\
\text { Zealand) }\end{array}$ & 92 & $72-121$ & $77-118$ & $835-1256$ & & & & a & & & \\
\hline
\end{tabular}

Maturity staging information not available

Some/all specimens unsexed

'Maturity staging information incomplete

d Insufficient number of specimens for analysis

${ }^{e}$ The representation of each maturity stage is inadequate - predominance of immature and juveniles

${ }^{\mathrm{f}}$ Insufficient number of hauls

${ }^{\mathrm{g}}$ Geographical position and depth not available

Depth not available

* Analysis performe 


\section{Table A3}

Compiled data available for the leafscale gulper shark by region and geographical Area. Data presented includes the number of sampled specimens ( $\mathrm{n}$ ), total length range $(T L$, in $\mathrm{cm}$ ) by sex and depth range of capture (in $\mathrm{m}$ ) for all the specimens; the number $(\mathrm{n}$ ), total length range (TL, in $\mathrm{cm}$ ) and depth range of capture (in $\mathrm{m}$ ) of all the sampled juveniles; the maximum number of specimens used in the analysis $(n)$ and the analysis carried out for each geographical area. Since there were some gaps for some variables in the datasets the number of sampled specimens might differ between analyses. CCA: constrained correspondence analysis; MAR: Mid-Atlantic Ridge; NA: information not available.

\begin{tabular}{|c|c|c|c|c|c|c|c|c|c|c|c|c|}
\hline \multirow[b]{2}{*}{ Region } & \multirow[b]{2}{*}{ Geographical Area } & \multicolumn{2}{|c|}{ All specimens } & \multirow[b]{2}{*}{$\begin{array}{l}\text { Females } \\
\text { TL range } \\
(\mathrm{cm})\end{array}$} & \multirow[b]{2}{*}{$\begin{array}{l}\text { Depth } \\
\text { range }(\mathrm{m})\end{array}$} & \multicolumn{3}{|c|}{ Juveniles information } & \multicolumn{2}{|c|}{ Analysis informatio } & \multirow[b]{2}{*}{$\begin{array}{l}\text { Sex } \\
\text { ratio }\end{array}$} & \multirow[b]{2}{*}{ CCA } \\
\hline & & $\mathbf{n}$ & $\begin{array}{l}\text { Males TL } \\
\text { range } \\
(\mathrm{cm})\end{array}$ & & & $\mathbf{n}$ & $\begin{array}{l}\mathrm{TL} \\
\text { range } \\
\text { (cm) }\end{array}$ & $\begin{array}{l}\text { Depth } \\
\text { range }(\mathrm{m})\end{array}$ & notes & $\mathbf{n}$ & & \\
\hline \multirow[t]{9}{*}{ NE ATLANTIC } & Iceland & 46 & $63-113$ & $98-145$ & $228-915$ & & & & & 46 & $*$ & $*$ \\
\hline & Rockall \& Hatton Banks & 2056 & $64-136$ & $70-135$ & $500-1930$ & & & & $b, c$ & 627 & $*$ & $*$ \\
\hline & Scotland & 720 & $65-143$ & $82-166$ & $416-1540$ & & & & & 713 & $*$ & $*$ \\
\hline & Ireland & 847 & $87-119$ & $77-138$ & $610-1459$ & & & & $b, c$ & 570 & $*$ & $*$ \\
\hline & Bay of Biscay & 16 & $91-110$ & $82-109$ & $1202-1293$ & & & & $\mathrm{~h}$ & & & \\
\hline & Portugal & 260 & $84-140$ & $35-139$ & $560-1606$ & 3 & $35-59$ & $550-650$ & & 255 & $*$ & $*$ \\
\hline & North Azores (MAR) & 333 & $95-120$ & $90-123$ & $467-3366$ & & & & $b, c$ & 83 & & \\
\hline & Madeira Archipelago & 205 & $89-118$ & $92-146$ & 1200 & & & & & 205 & $*$ & $*$ \\
\hline & Canarias Archipelago & 74 & $83-115$ & $76-133$ & $750-3150$ & & & & & 74 & $*$ & $*$ \\
\hline CE ATLANTIC & Mauritania & 86 & $41-101$ & $43-116$ & $650-930$ & 45 & $41-60$ & $621-1639$ & & 86 & $*$ & \\
\hline SE ATLANTIC & Namibia & 13 & $44-112$ & $49-142$ & $504-1553$ & 4 & $44-60$ & $551-793$ & $d$ & & & \\
\hline \multirow[t]{2}{*}{ SW PACIFIC } & $\begin{array}{l}\text { Chatham Rise \& North Island } \\
\text { (New Zealand) }\end{array}$ & 407 & $37-115$ & $31-140$ & $361-1251$ & 170 & $31-60$ & $361-1096$ & & 407 & $*$ & $*$ \\
\hline & $\begin{array}{l}\text { South Island, Campbell } \\
\text { Plateau (New Zealand) }\end{array}$ & 417 & $25-121$ & $39-142$ & 477-999 & 260 & $25-60$ & 477-999 & & 417 & $*$ & $*$ \\
\hline $\begin{array}{l}\text { a Maturity stagin } \\
{ }^{b} \text { Some/all specin } \\
{ }^{c} \text { Maturity stagin } \\
{ }^{d} \text { Insufficient num } \\
{ }^{\text {e }} \text { The representat } \\
{ }^{f} \text { Insufficient num } \\
{ }^{g} \text { Geographical pc } \\
{ }^{h} \text { Depth not availa } \\
{ }^{*} \text { Analysis perfor }\end{array}$ & $\begin{array}{l}\text { ginformation not available } \\
\text { ens unsexed } \\
\text { g information incomplete } \\
\text { hber of specimens for analysis } \\
\text { ion of each maturity stage is inade } \\
\text { ber of hauls } \\
\text { sition and depth not available } \\
\text { ble } \\
\text { med }\end{array}$ & uate $-p$ & redominance & of immatu & e and juvenile & & & & & & & \\
\hline
\end{tabular}




\section{Table A4}

Compiled data available for the birdbeak dogfish by region and geographical Area. Data presented includes the number of sampled specimens ( $\mathrm{n}$ ), total length range (TL, in $\mathrm{cm}$ ) by sex and depth range of capture (in $\mathrm{m}$ ) for all the specimens; the number ( $\mathrm{n}$ ), total length range (TL, in $\mathrm{cm}$ ) and depth range of capture (in $\mathrm{m}$ ) of all the sampled juveniles; the number of specimens used in the analysis $(n)$ and the analysis carried out for each geographical area. Since there were some gaps for some variables in the datasets the number of sampled specimens might differ between analyses. CCA: constrained correspondence analysis; MAR: Mid-Atlantic Ridge; NA: information not available.

\begin{tabular}{|c|c|c|c|c|c|c|c|c|c|c|c|c|}
\hline \multirow[b]{2}{*}{ Region } & \multirow[b]{2}{*}{ Geographical Area } & \multicolumn{4}{|c|}{ All specimens } & \multicolumn{3}{|c|}{ Juveniles information } & \multicolumn{2}{|c|}{ Analysis information } & \multirow[b]{2}{*}{$\begin{array}{l}\text { Sex } \\
\text { ratio }\end{array}$} & \multirow[b]{2}{*}{ CCA } \\
\hline & & $\mathbf{n}$ & $\begin{array}{l}\text { Males TL } \\
\text { range } \\
(\mathrm{cm})\end{array}$ & $\begin{array}{l}\text { Females } \\
\text { TL range } \\
(\mathrm{cm})\end{array}$ & $\begin{array}{l}\text { Depth } \\
\text { range }(\mathrm{m})\end{array}$ & $\mathbf{n}$ & $\begin{array}{l}\text { TL } \\
\text { range } \\
\text { (cm) }\end{array}$ & $\begin{array}{l}\text { Depth } \\
\text { range }(m)\end{array}$ & notes & $\mathbf{n}$ & & \\
\hline \multirow[t]{9}{*}{ NE ATLANTIC } & Iceland & 259 & $71-97$ & $66-126$ & $437-921$ & & & & $b, c$ & 251 & $*$ & $*$ \\
\hline & Rockall \& Hatton Banks & 1504 & $42-94$ & $35-112$ & $262-1355$ & 10 & $35-49$ & $1092-1355$ & $b, c$ & 377 & $*$ & $*$ \\
\hline & Scotland & 332 & $58-97$ & $66-114$ & $416-1504$ & & & & & 330 & $*$ & $*$ \\
\hline & Ireland & 2426 & $55-109$ & $52-162$ & $500-1378$ & 2 & $52-55$ & 883 & $b, c$ & 1503 & $*$ & $*$ \\
\hline & Bay of Biscay & 172 & $73-93$ & $62-113$ & 1151-1339 & & & & $\mathrm{h}$ & 166 & $*$ & $*$ \\
\hline & Portugal & 33 & --- & $28-142$ & $660-1000$ & 5 & $28-32$ & $660-740$ & & 33 & $*$ & $*$ \\
\hline & North Azores (MAR) & 67 & 81 & 85-105 & $651-1100$ & & & & $b, c$ & & & \\
\hline & South Azores (MAR) & 82 & $85-90$ & $97-111$ & $412-691$ & & & & $b, c$ & & & \\
\hline & Canarias Archipelago & 56 & $80-88$ & $57-113$ & $600-1300$ & & & & & 51 & $*$ & * \\
\hline CE ATLANTIC & Mauritania & 1264 & $27-99$ & $26-136$ & $738-1412$ & 490 & $26-55$ & 739-1399 & & 1264 & $*$ & * \\
\hline SE ATLANTIC & Namibia & 324 & $38-93$ & $41-111$ & $551-1492$ & 133 & $38-60$ & $551-1900$ & & 324 & $*$ & $*$ \\
\hline \multirow[t]{2}{*}{ NW ATLANTIC } & U.S. East Coast & 23 & $59-89$ & $38-101$ & $830-1141$ & 2 & $37-38$ & $830-1141$ & $d, e$ & & & \\
\hline & Gulf of Mexico & 4 & --- & $78-102$ & $524-714$ & & & & $d$ & & & \\
\hline \multirow[t]{2}{*}{ SW PACIFIC } & $\begin{array}{l}\text { Chatham Rise \& North Island } \\
\text { (New Zealand) }\end{array}$ & 7540 & $28-100$ & 20-120 & $350-1478$ & 1769 & $20-55$ & $350-1120$ & & 7508 & $*$ & $*$ \\
\hline & $\begin{array}{l}\text { South Island, Campbell Plateau } \\
\text { (New Zealand) }\end{array}$ & 382 & $29-96$ & $29-116$ & $457-984$ & 11 & $29-39$ & $670-959$ & & 382 & * & $*$ \\
\hline $\begin{array}{l}\text { a Maturity staging } \\
{ }^{\mathrm{b}} \text { Some/all specim } \\
{ }^{\mathrm{c}} \text { Maturity staging } \\
\mathrm{d} \text { Insufficient num } \\
{ }^{\mathrm{e}} \text { The representat } \\
{ }^{\mathrm{f}} \text { Insufficient num } \\
{ }^{\mathrm{g}} \text { Geographical po } \\
{ }^{\mathrm{h}} \text { Depth not availa } \\
\text { * } \text { Analysis perforn }\end{array}$ & $\begin{array}{l}\text { information not available } \\
\text { hens unsexed } \\
\text { information incomplete } \\
\text { ber of specimens for analysis } \\
\text { ion of each maturity stage is inadequ } \\
\text { ber of hauls } \\
\text { sition and depth not available } \\
\text { ble } \\
\text { ned }\end{array}$ & late $-p r$ & dominance o & fimmature & and juveniles & & & & & & & \\
\hline
\end{tabular}



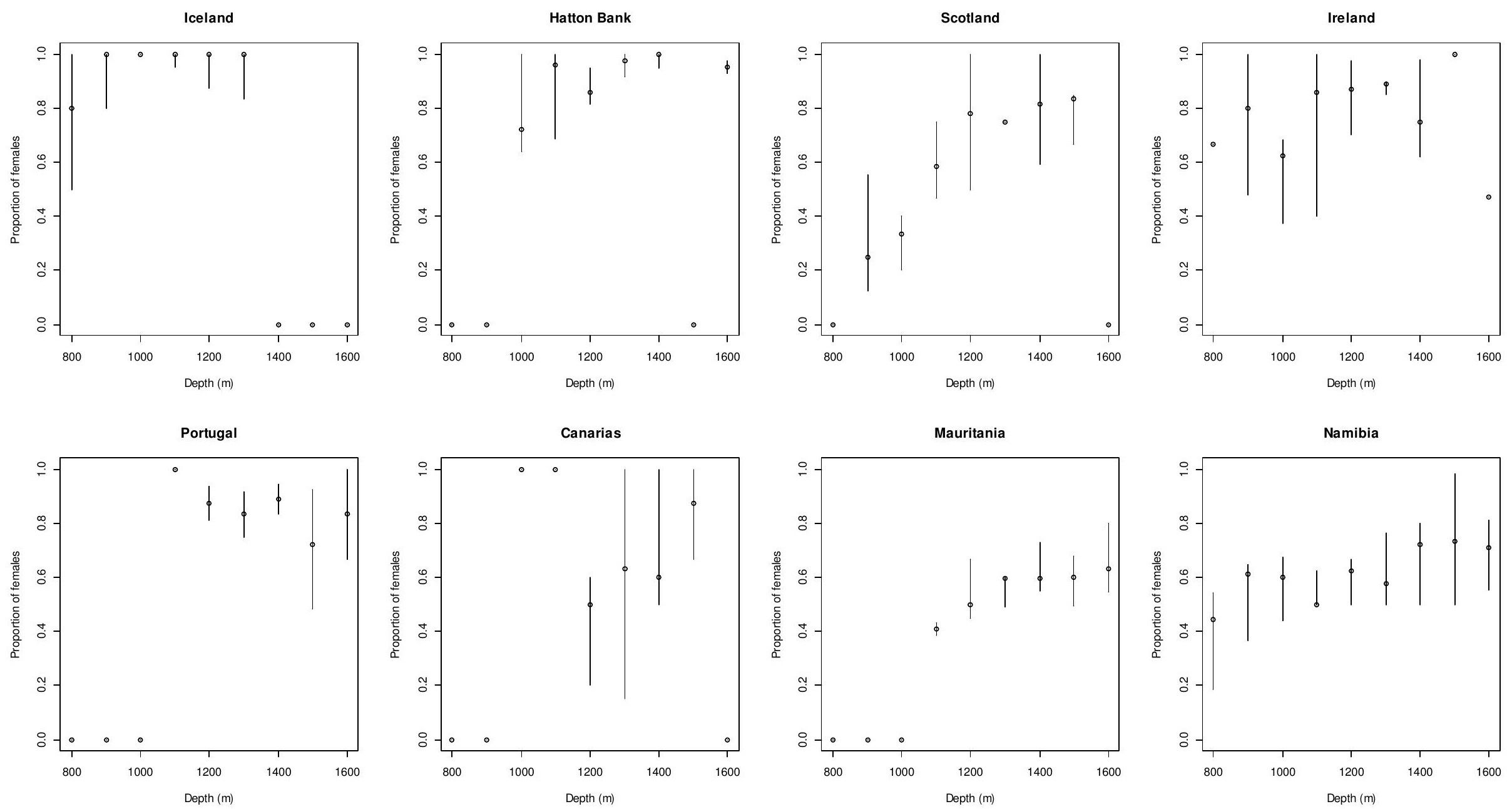

Fig. A1. Portuguese dogfish. Median and interquartile range of the proportion of females by depth strata $(100 \mathrm{~m})$ by geographical area. Depth was constrained to 800 to $1700 \mathrm{~m}$. Only hauls with two or more individuals were selected and among these, only geographical areas with 25 or more hauls were selected for the analysis. 


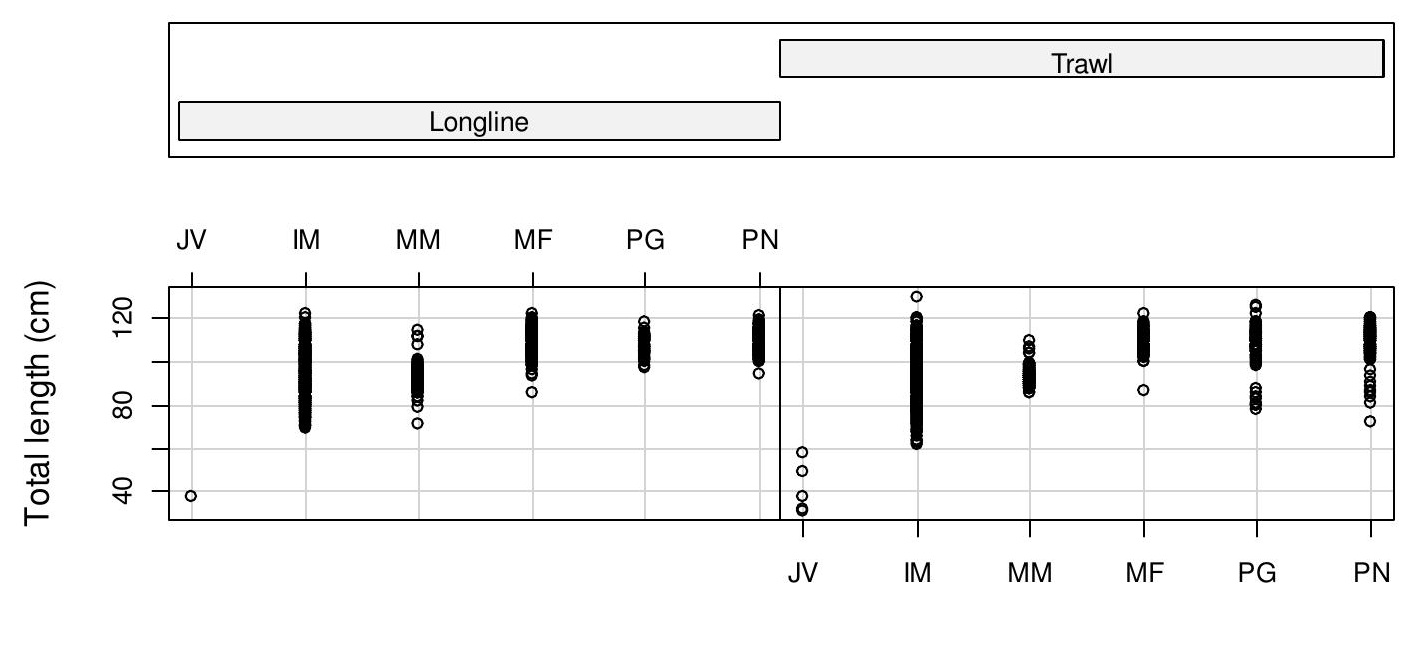

Maturity stage

Fig. A2. Portuguese dogfish. Relationship Total length $(\mathrm{cm})$ by maturity stage and type of gear (longline or trawl) in the NE Atlantic ( $n=2887)$. JV: juveniles; IM: immatures; MM: mature males; MF: mature females; PG: pregnant females; PN: post-natal females. 
Hatton Bank
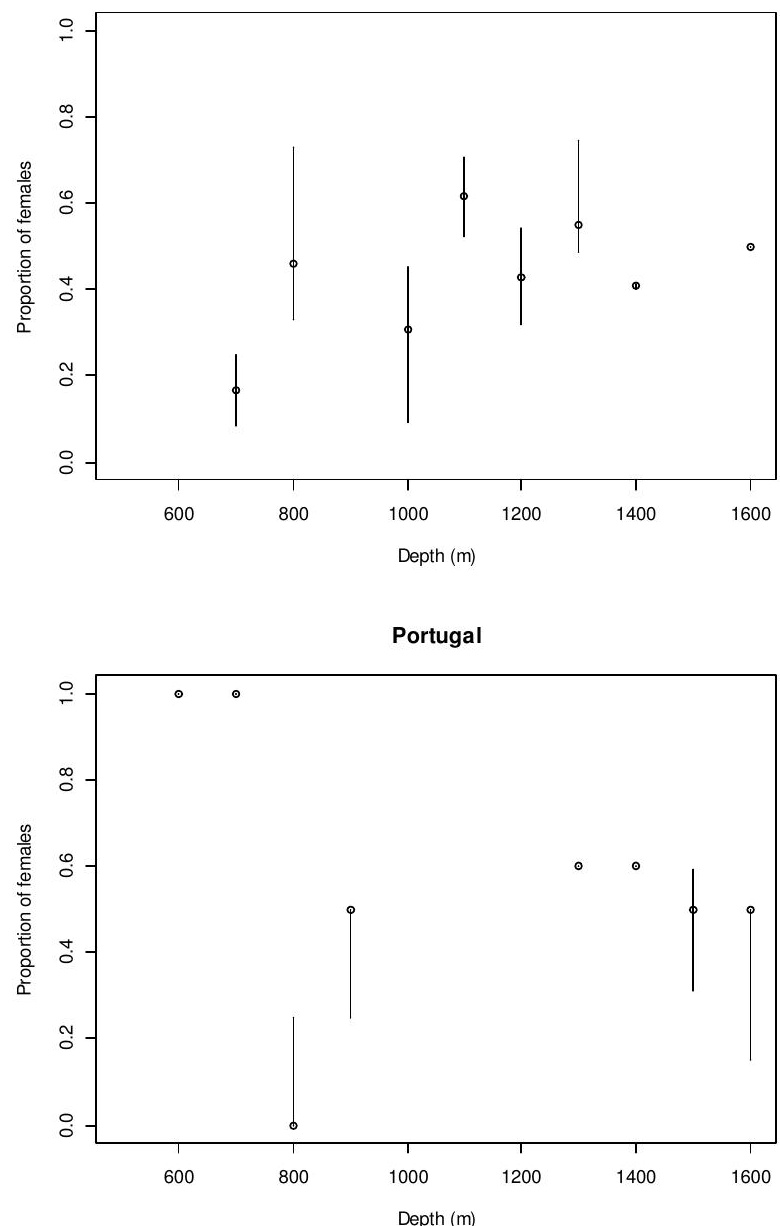

Scotland

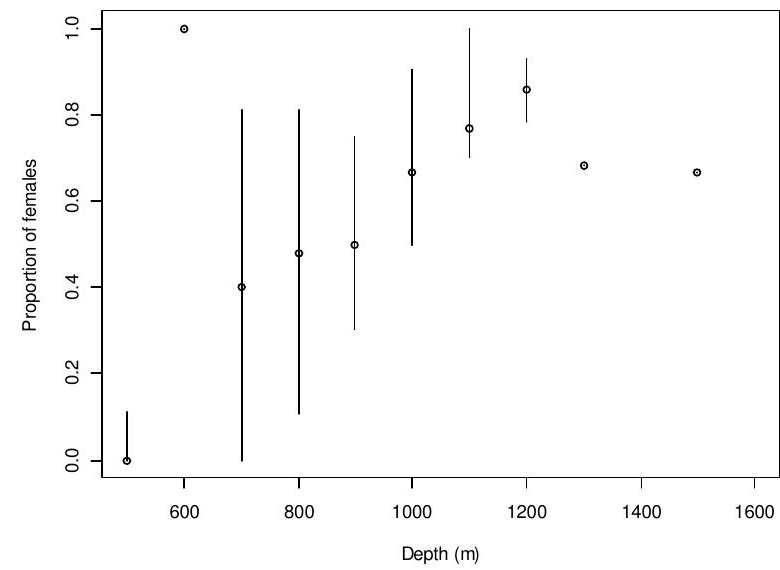

Chatham Rise, North I.

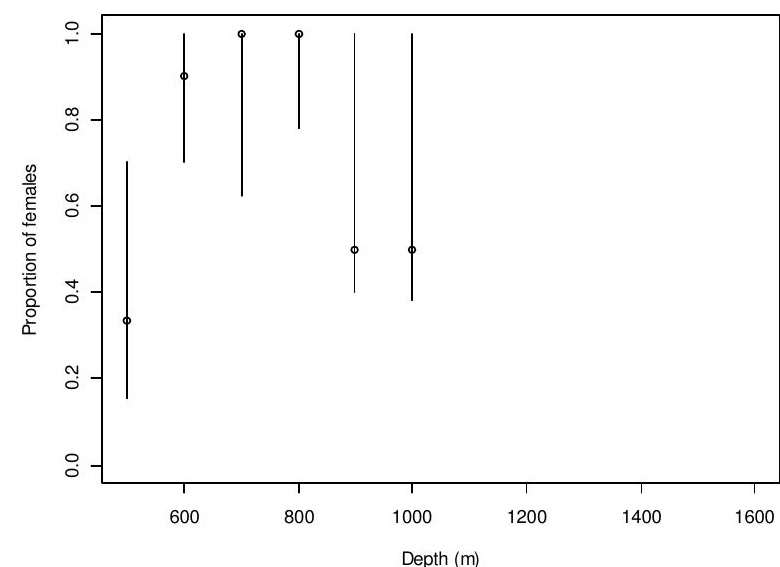

Ireland

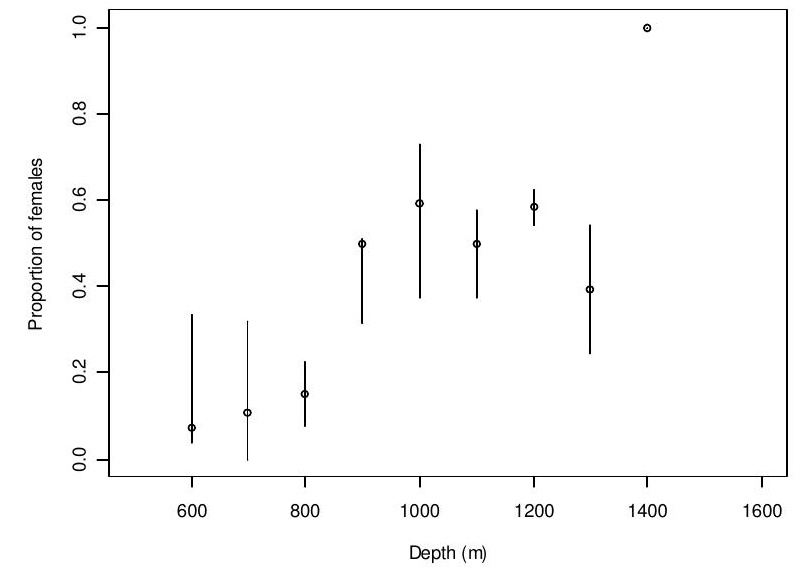

South I., Campbell PI.

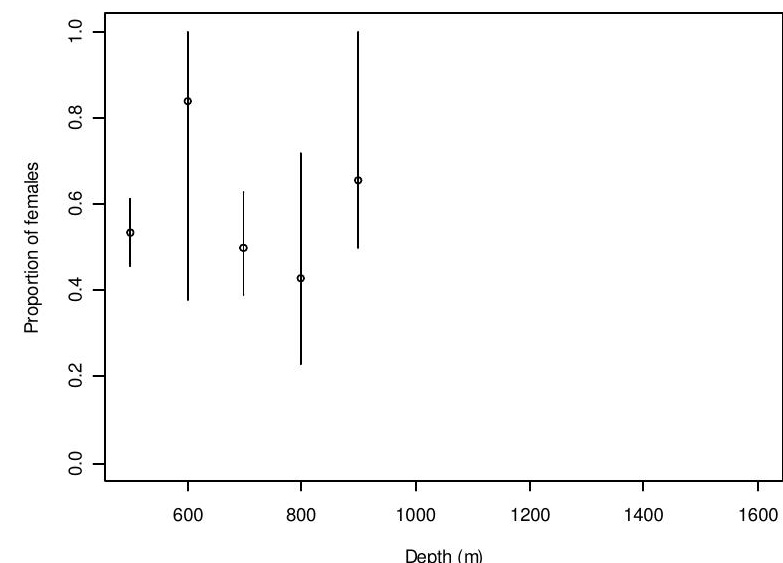

Fig. A3. Leafscale gulper shark. Median and interquartile range of the proportion of females by depth strata (100 $\mathrm{m}$ ) by geographical area. Depth was constrained to 500 to $1700 \mathrm{~m}$. Only hauls with two or more individuals were selected and among these, only geographical areas with 25 or more hauls were selected for the analysis. 
Leafscale gulper shark, NE Atlantic
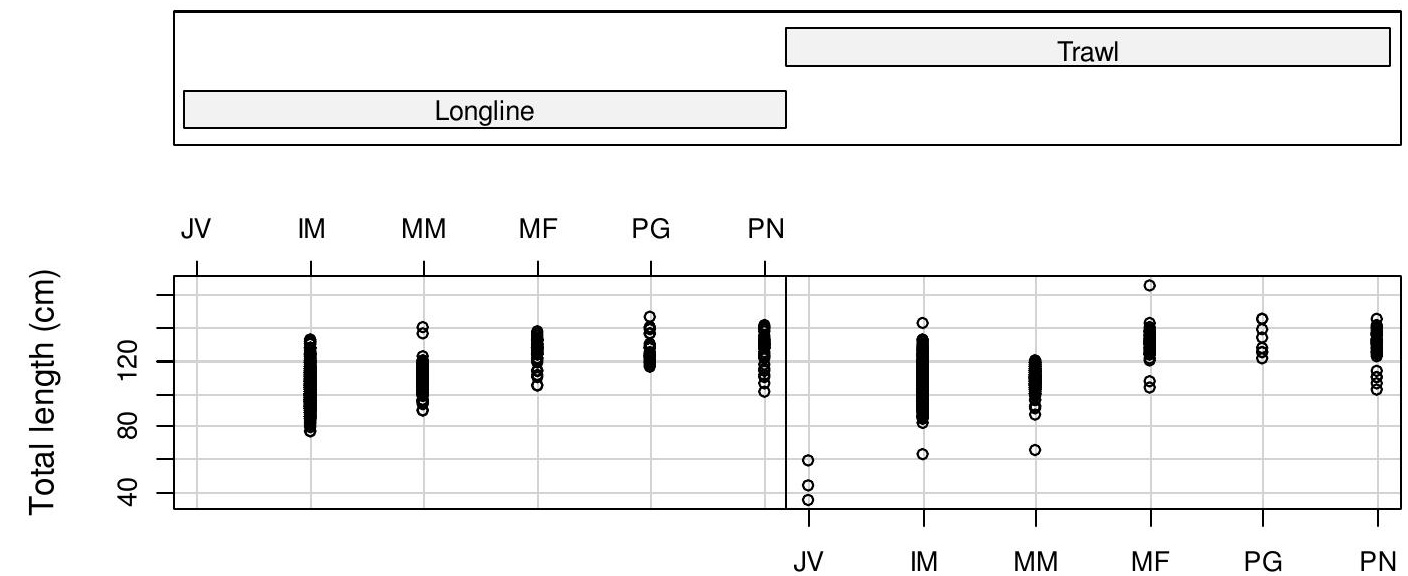

Maturity stage

Fig. A4. Leafscale gulper shark. Total length $(\mathrm{cm})$ by maturity stage and type of gear (longline or trawl) in the NE Atlantic ( $\mathrm{n}=2573)$. JV: juveniles; IM: immatures; MM: mature males; MF: mature females; PG: pregnant females; PN: post-natal females. 

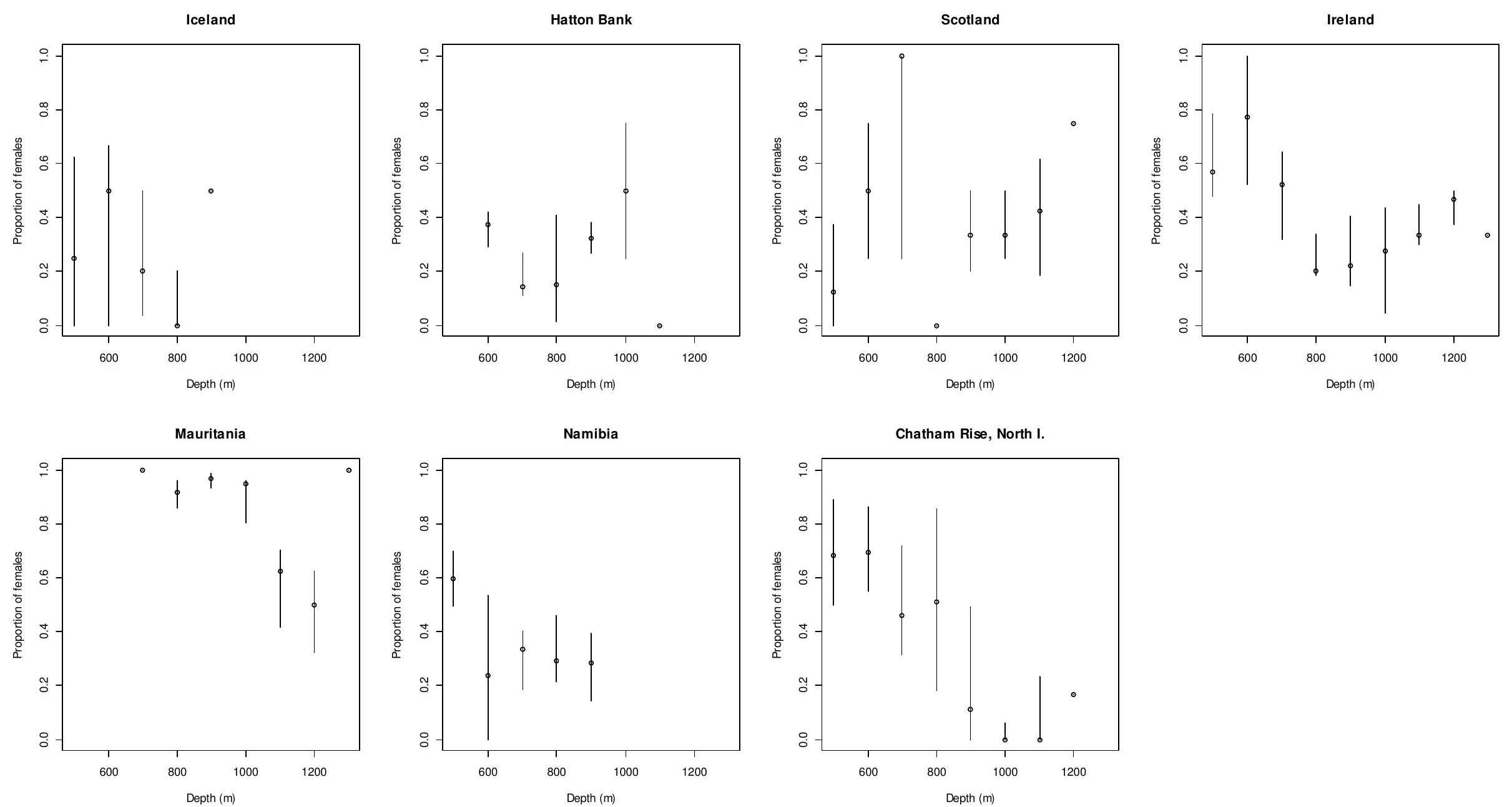

Fig. A5. Birdbeak dogfish. Median and interquartile range of the proportion of females by depth strata $(100 \mathrm{~m})$ by geographical area. Depth was constrained to 500 to $1400 \mathrm{~m}$. Only hauls with two or more individuals were selected and among these, only geographical areas with 25 or more hauls were selected for the analysis. 
Birdbeak dogfish, NE Atlantic
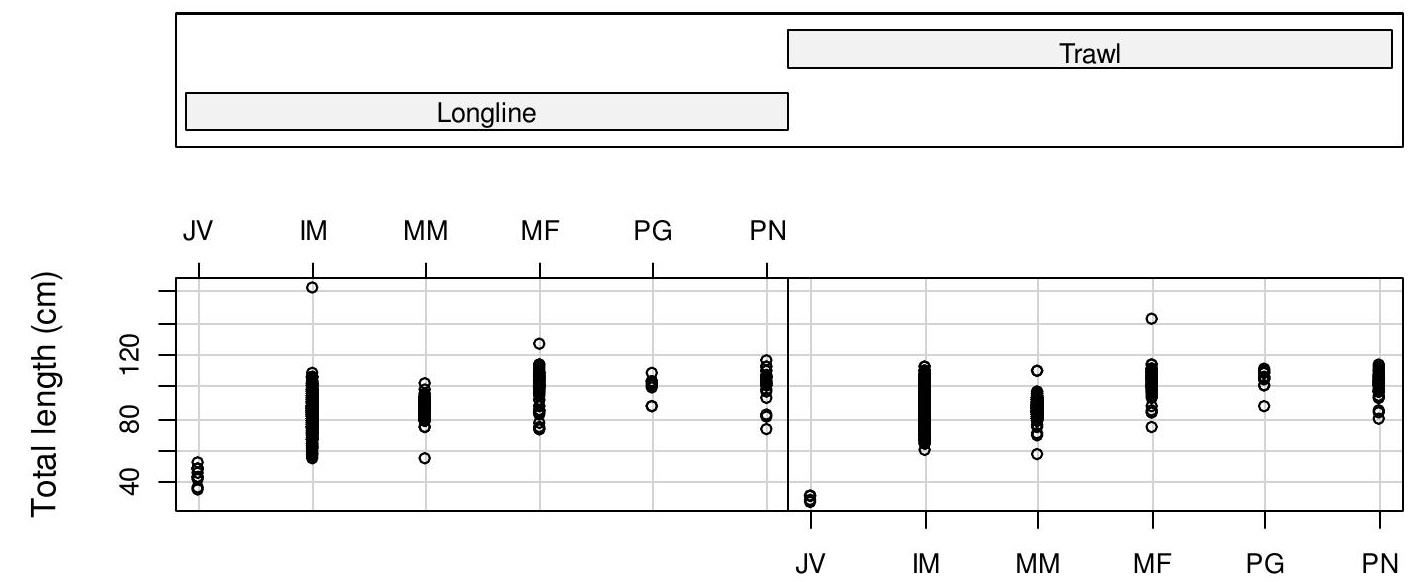

Maturity stage

Fig. A6. Birdbeak dogfish. Total length $(\mathrm{cm})$ by maturity stage and type of gear (longline or trawl) in the NE Atlantic ( $n=2711 \mathrm{JV}$ : juveniles; IM: immatures; MM: mature males; MF: mature females; PG: pregnant females; PN: post-natal females. 